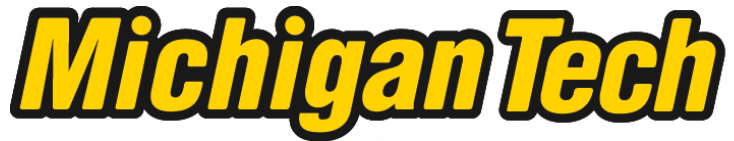 \\ Michigan Technological University Create the Future Digital Commons @ Michigan Tech
}

Characterizations of partially reduced polyoxometalate catalysts using ammonia adsorption microcalorimetry and methanol oxidation studies / by Suresh Babu Bommineni.

Suresh Babu Bommineni

Michigan Technological University

Follow this and additional works at: https://digitalcommons.mtu.edu/etds

Part of the Chemical Engineering Commons

Copyright 2011 Suresh Babu Bommineni

Recommended Citation

Bommineni, Suresh Babu, "Characterizations of partially reduced polyoxometalate catalysts using ammonia adsorption microcalorimetry and methanol oxidation studies / by Suresh Babu Bommineni.", Master's Thesis, Michigan Technological University, 2011.

https://doi.org/10.37099/mtu.dc.etds/2

Follow this and additional works at: https://digitalcommons.mtu.edu/etds

Part of the Chemical Engineering Commons 


\title{
CHARACTERIZATIONS OF PARTIALLY REDUCED POLYOXOMETALATE CATALYSTS USING AMMONIA ADSORPTION MICROCALORIMETRY AND METHANOL OXIDATION STUDIES
}

\author{
By \\ Suresh Babu Bommineni
}

\begin{abstract}
A THESIS
Submitted in partial fulfillment of the requirements for the degree of MASTER OF SCIENCE (CHEMICAL ENGINEERING)
\end{abstract}

MICHIGAN TECHNOLOGICAL UNIVERSITY

2011

(C) 2010 Suresh Babu Bommineni 
This thesis, "Characterizations of Partially Reduced Polyoxometalate Catalysts Using Ammonia Adsorption Microcalorimetry and Methanol Oxidation Studies,“" is hereby approved in partial fulfillment of the requirements for the Degree of MASTER OF SCIENCE IN CHEMICAL ENGINEERING.

\section{DEPARTMENT:}

Chemical Engineering

Signatures:

Thesis Advisor

Dr. Joseph H. Holles

Department Chair

Dr. Surendra K. Kawatra

Date 


\section{Acknowledgements}

I am always thankful to my advisor, Dr. Joseph H Holles, for giving me an opportunity to work for one of the leading research in Chemical Engineering Industry. His sincere efforts and his constant encouragement throughout my Masters degree have been so profound. His support at every level of my research had always been my strength to achieve the progressive results.

I appreciate Mr. Dean Seppala efforts for helping me in fixing the GCMS, without whom I wouldn't have achieved the results in expected time frame. My lab mate, Michael D. Skoglund, also have been very supportive in helping me conduct the experiments.

I would like to thank Dr. Holles and Dr. Mullins for providing me an opportunity to work under them as Teaching Assistant during which I had a chance to revise my fundamentals and also improve my inter-personal skills. I would also like to thank the Head of the

Chemical Engineering Department, Dr. Kawatra, for providing me a Teaching Assistantship during summer'09.

Last but not the least, I am always thankful to my friends and family members who have been part of my life and always stood my side at every level. During my Bachelors Degree, I always aspired for a challenging \& rewarding higher education and Michigan Tech made it possible for me for which I am always thankful for! 


\begin{abstract}
Phosphomolybdic acid $\left(\mathrm{H}_{3} \mathrm{PMo}_{12} \mathrm{O}_{40}\right)$ along with niobium,pyridine and niobium exchanged phosphomolybdic acid catalysts were prepared. Ammonia adsorption microcalorimetry and methanol oxidation studies were carried out to investigate the acid sites strength acid/base/redox properties of each catalyst. The addition of niobium, pyridine or both increased the ammonia heat of adsorption and the total uptake. The catalyst with both niobium and pyridine demonstrated the largest number of strong sites. For the parent $\mathrm{H}_{3} \mathrm{PMo}_{12} \mathrm{O}_{40}$ catalyst, methanol oxidation favors the redox product. Incorporation of niobium results in similar selectivity to redox products but also results in no catalyst deactivation. Incorporation of pyridine instead changes to the selectivity to favor the acidic product. Finally, the inclusion of both niobium and pyridine results in strong selectivity to the acidic product while also showing no catalyst deactivation. Thus the presence of pyridine appears to enhance the acid property of the catalyst while niobium appears to stabilize the active site.
\end{abstract}




\section{Table of Contents}

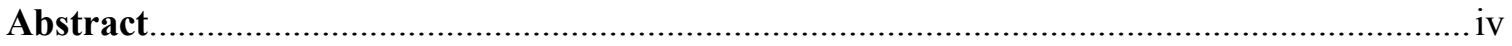

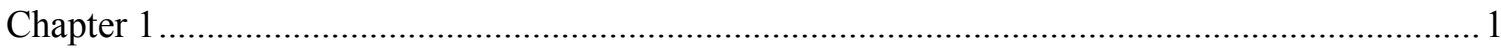

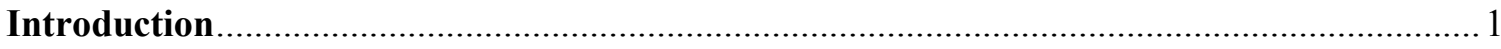

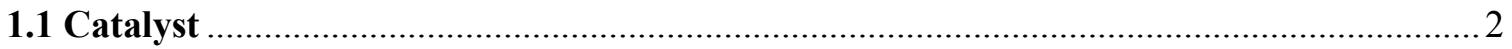

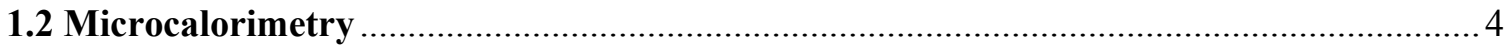

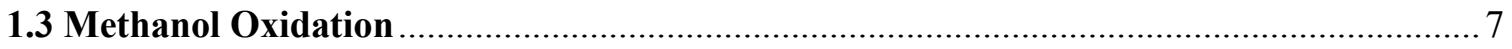

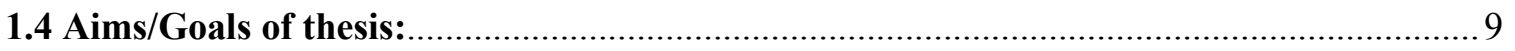

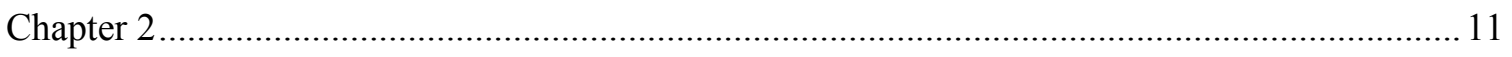

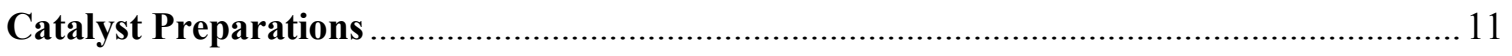

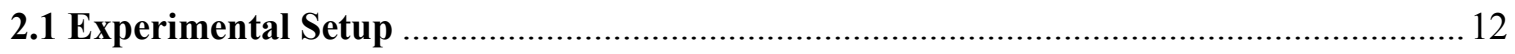

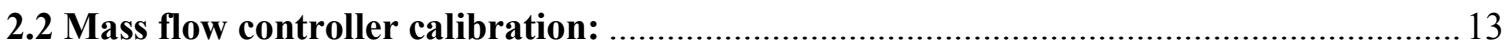

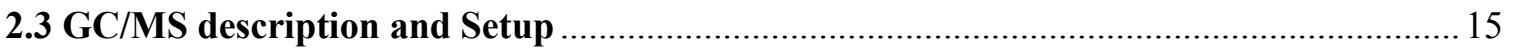

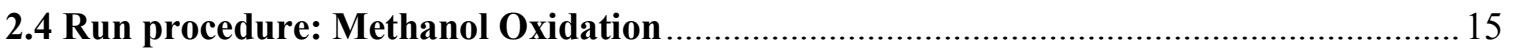

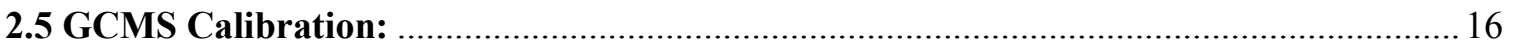

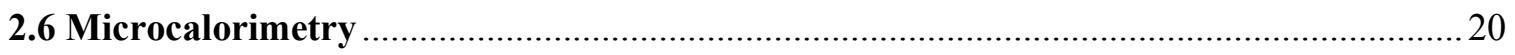

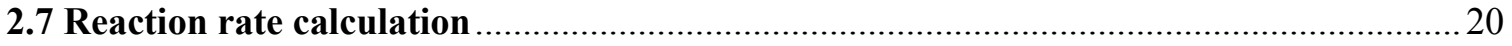

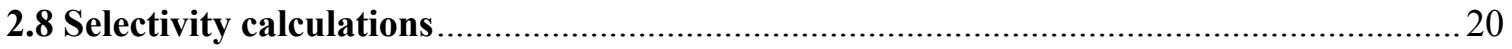

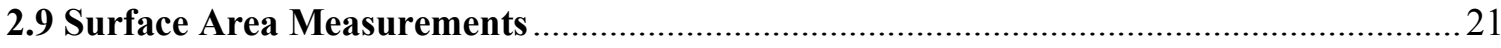

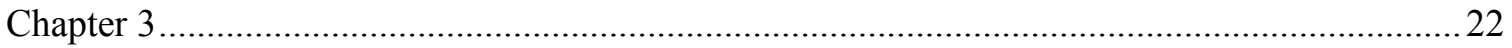

Characterization of Partially Reduced Polyoxometalate Catalysts Using Ammonia Adsorption Microcalorimetry and Methanol Oxidation Studies........................................22

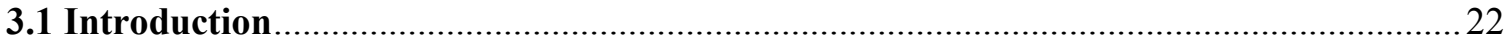

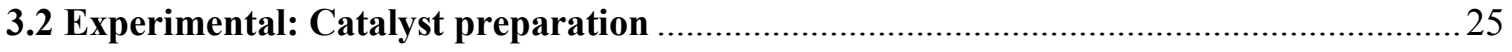

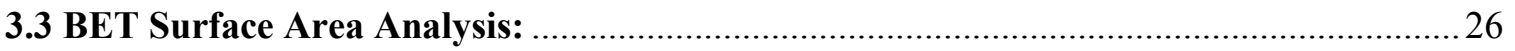

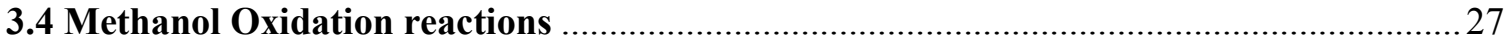




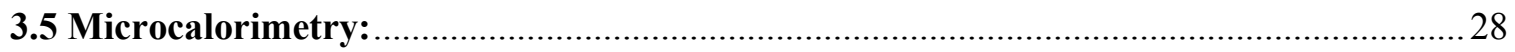

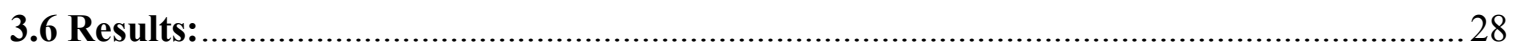

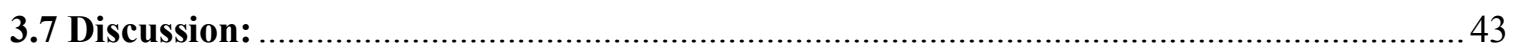

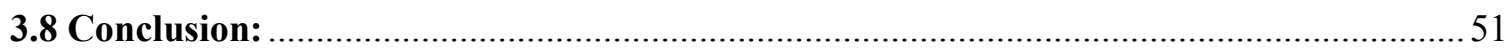

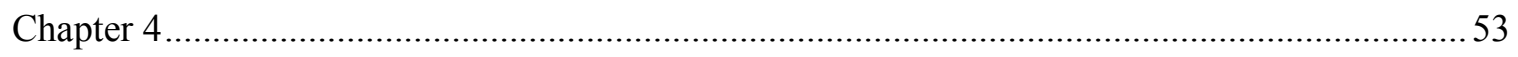

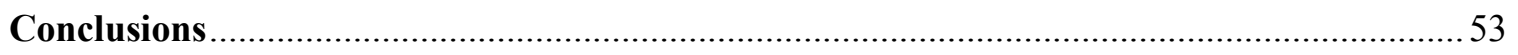

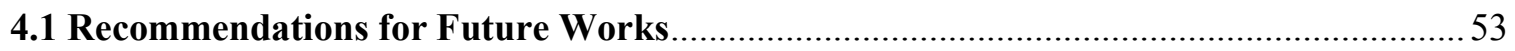

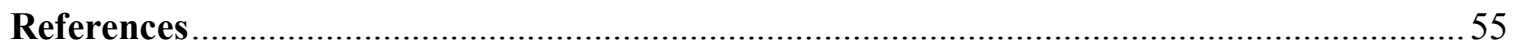

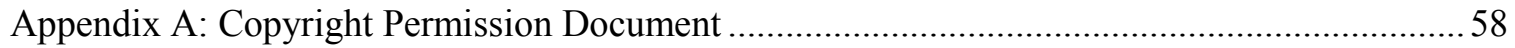




\section{List of Figures and Tables}

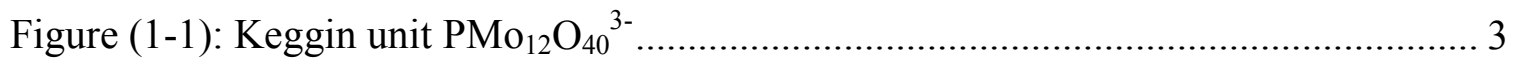

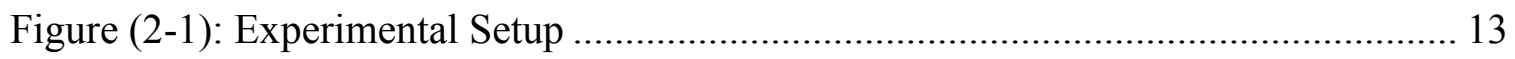

Figure (2-2): Helium Mass Flow Controller Calibration Results .................................... 14

Figure (2-3): Oxygen Mass Flow Controller Calibration Results ..................................... 14

Figure (2-4): Calibration Curve for Methanol (GC/MS) ................................................. 18

Figure (2-5): Calibration Curve for Formaldehyde (GC/MS) ………………………..... 18

Figure (2-6): Calibration Curve for Dimethoxymethane (GC/MS) ................................. 19

Figure (2-7): Calibration Curve for Dimethyl Ether (GC/MS) ...................................... 19

Table 1: Surface Area Measurements ……………………..................................... 29

Figure (3-1) - $\mathrm{NH}_{3}$ uptake and heat of adsorption of the catalysts showing the active sites.

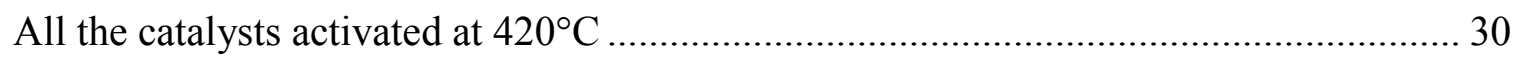

Figure (3-2) - $\mathrm{NH}_{3}$ uptake and heat of adsorption of the catalysts showing the active sites.

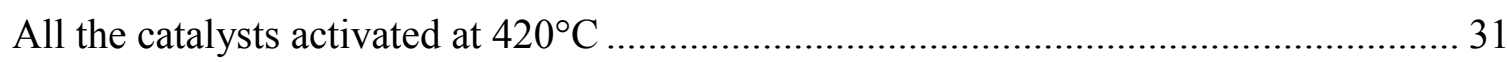

Figure (3-3) - Conversion and selectivity of $\mathrm{H}_{3} \mathrm{PMo}_{12} \mathrm{O}_{40}$ catalyst as a function of time. The reaction was carried out at $260^{\circ} \mathrm{C}$ and with $0.02 \mathrm{~g}$ of catalyst and a total flowrate of

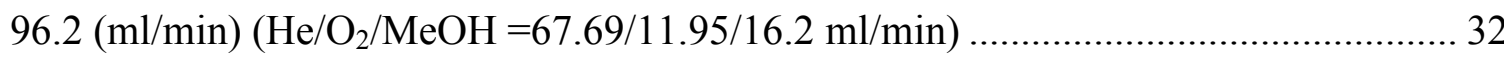

Figure (3-4) - Selectivity of all products as a function of time of $\mathrm{H}_{3} \mathrm{PMo}_{12} \mathrm{O}_{40}$ catalyst. The reaction was carried out at $260^{\circ} \mathrm{C}$ and with $0.02 \mathrm{~g}$ of catalyst and a total flowrate of

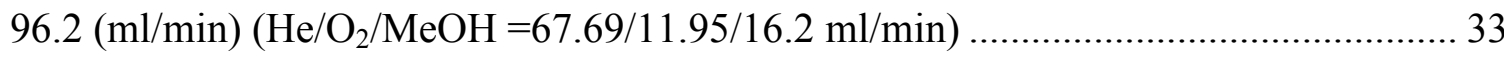

Figure (3-5) - Conversion and selectivity of $\mathrm{NbPMo}_{12} \mathrm{O}_{40}$ catalyst as a function of time. The reaction was carried out at $260^{\circ} \mathrm{C}$ and with $0.04 \mathrm{~g}$ of catalyst and a total flowrate of $108.2(\mathrm{ml} / \mathrm{min})\left(\mathrm{He} / \mathrm{O}_{2} / \mathrm{MeOH}=76.5 / 13.5 / 18.2 \mathrm{ml} / \mathrm{min}\right)$.

Figure (3-6) - Selectivity of all products as a function of time of $\mathrm{NbPMo}_{12} \mathrm{O}_{40}$ catalyst. The reaction was carried out at $260^{\circ} \mathrm{C}$ and with $0.04 \mathrm{~g}$ of catalyst and a total flowrate of $108.2(\mathrm{ml} / \mathrm{min})\left(\mathrm{He} / \mathrm{O}_{2} / \mathrm{MeOH}=76.5 / 13.5 / 18.2 \mathrm{ml} / \mathrm{min}\right)$. 
Figure (3-7) - Conversion and selectivity of $\mathrm{PMo}_{12} \mathrm{O}_{40} \mathrm{Pyr}$ catalyst as a function of time. The reaction was carried out at $260^{\circ} \mathrm{C}$ and with $0.04 \mathrm{~g}$ of catalyst and a total flowrate of $108.2(\mathrm{ml} / \mathrm{min})\left(\mathrm{He} / \mathrm{O}_{2} / \mathrm{MeOH}=76.5 / 13.5 / 18.2 \mathrm{ml} / \mathrm{min}\right)$.

Figure (3-8) - Selectivity of all products as a function of time of $\mathrm{PMo}_{12} \mathrm{O}_{40} \mathrm{Pyr}$ catalyst. The reaction was carried out at $260^{\circ} \mathrm{C}$ and with $0.04 \mathrm{~g}$ of catalyst and a total flowrate of $108.2(\mathrm{ml} / \mathrm{min})\left(\mathrm{He} / \mathrm{O}_{2} / \mathrm{MeOH}=76.5 / 13.5 / 18.2 \mathrm{ml} / \mathrm{min}\right)$

Figure (3-9) - Conversion and selectivity of $\mathrm{NbPMo}_{12} \mathrm{O}_{40} \mathrm{Pyr}$ catalyst as a function of time. The reaction was carried out at $260^{\circ} \mathrm{C}$ and with $0.01 \mathrm{~g}$ of catalyst and a total flowrate of $157.3(\mathrm{ml} / \mathrm{min})\left(\mathrm{He} / \mathrm{O}_{2} / \mathrm{MeOH}=115.2 / 20.44 / 27.34 \mathrm{ml} / \mathrm{min}\right)$.

Figure (3-10) - Selectivity of all products as a function of time of $\mathrm{NbPMo}_{12} \mathrm{O}_{40} \mathrm{Pyr}$ catalyst. The reaction was carried out at $260^{\circ} \mathrm{C}$ and with $0.01 \mathrm{~g}$ of catalyst and a total flowrate of $157.3(\mathrm{ml} / \mathrm{min})\left(\mathrm{He} / \mathrm{O}_{2} / \mathrm{MeOH}=115.2 / 20.44 / 27.34 \mathrm{ml} / \mathrm{min}\right)$........................... 40

Table 2: Reactivity of the catalyst $\left(\mathrm{mmol} / \mathrm{min}^{2}\right)$ at $260^{\circ} \mathrm{C}$, around $10 \%$ conversion... 41

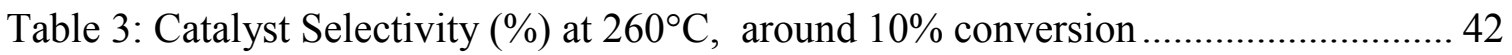




\section{Chapter 1}

\section{Introduction}

In modern chemical industries today, more than $60 \%$ of the chemicals and intermediates synthesized via catalytic processes are done by oxidation $[1,2]$. Oxidation reactions play an important role in the total catalytic oxidation where the desired products are obtained and also the destruction of undesired products [3]. In catalytic selective oxidation reactions the surface acidity/basicity and redox properties of the metal oxides play an important role.

Selective oxidation is extensively carried out on light hydrocarbons or alkanes like ethane, propane and butane[4], to obtain products such as acetic acid, acrylic acid and maleic acid. The work is focusing on ethane and propane because they are readily available and cheap[1]. Production of acetic acid and acrylic acid from ethane and propane are not commercial today. Production of maleic acid from butane is commercial in industry today. One of the well known selective oxidation reaction that is commercial in industry today is the conversion of n-butane to maleic anhydride over vanadium phosphorous oxide catalyst $[1,2]$.

In the chemical industries, the selective oxidations of hydrocarbon reactions continue to play an important role, resulting in ongoing investigation of the heterogeneous catalysts that accomplish these reactions. Polyoxometalates and phosphomolybdates have been extensively investigated for the selective oxidation of light alkanes [5-7]. The reason that these heterogeneous catalysts and their salts are usually investigated for their ability to 
perform selective oxidation reactions is because their structure and composition can be finely controlled. One of the major challenges is to determine the surface active sites on the metal oxides to understand the fundamental catalytic relationships for metal oxide catalysts [8]. The nature of active sites, their number and their strength on the catalyst surface, determines the selectivity and conversion capabilities of the catalyst. The nature of the oxide, the charge and the radius of the metal ions, will have an effect on the acidity and basicity of the catalyst [9].

\subsection{Catalyst}

The commercial use of heteropolyacid catalysts (HPA's) in some process have already been carried out. One of the main advantages is the reduced need for separation of solid heteropolyacids over liquid acids.[10-13] . The HPA's consists of primary, secondary and tertiary structures. Keggin - type HPA's are the most commonly known primary structure and are also thermally stable [14]. A simple Keggin unit is shown in figure (11). The general formula for the keggin-type HPA is $\mathrm{QM}_{12} \mathrm{O}_{40}{ }^{\mathrm{x}-}$, where $\mathrm{Q}$ is the central atom consisting of either $\mathrm{P}, \mathrm{Si}$ or $\mathrm{Ge}$ and $\mathrm{M}$ being the transition-metal atom commonly consisting of either molybdenum or tungsten and $\mathrm{x}$ being the charge on the structure. The central atom of a primary structure consists of tetrahedral arrangement of oxygen atoms which is surrounded by 12 oxygen octahedra-transition-metal. A keggin unit consists of four types of oxygen atoms, one central oxygen atom, one terminal oxygen atom and two different types of bridging atoms $[10,15]$. The bridging atoms form single bonds to the two different transition-metal atoms, and the double bond to a single transition-metal atom is formed by the terminal oxygen atom[13]. When the keggin unit is located at the 
lattice position, the secondary structure takes the form of Bravais lattices. The number of waters of hydration found in the solid will determine if it is a secondary structure[12]. Water bridges are formed in the secondary structure when the water of crystallization in the HPA's binds the keggin units.[13] . When heavy alkali salts are present or produced, tertiary structures are formed[13].

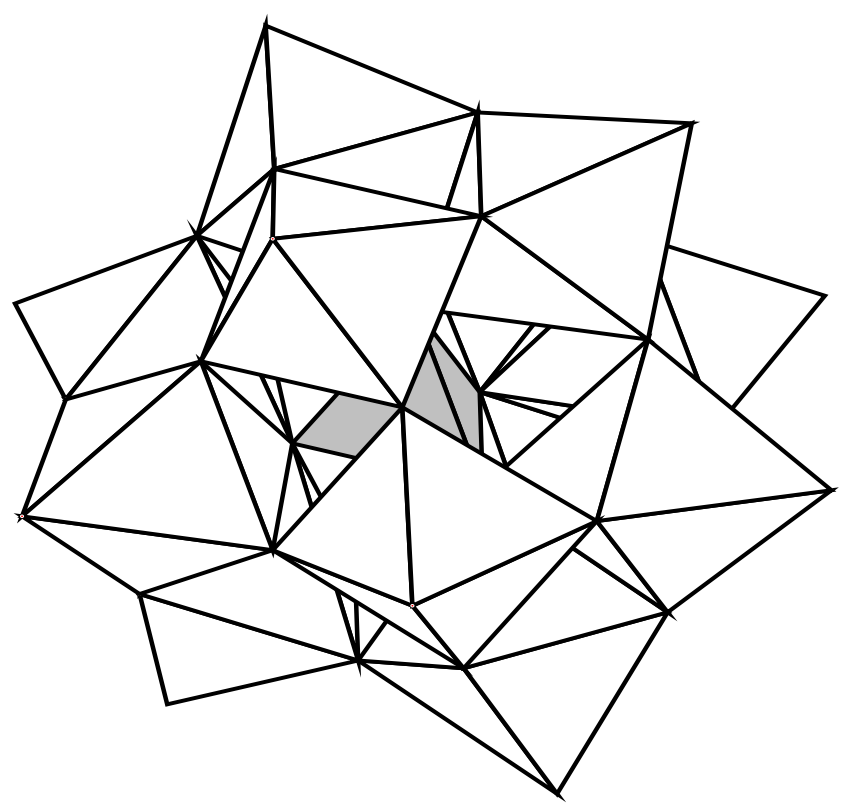

Figure (1-1): Keggin unit $\mathrm{PMo}_{12} \mathrm{O}_{40}{ }^{3-}$ [1]

See $\underline{\text { Appendix A }}$ for documentation of permission to republish this figure. 
In this work, the catalysts that are investigated include:

1) $\mathrm{H}_{3} \mathrm{PMo}_{12} \mathrm{O}_{40} \quad$ [Phosphomolybdic acid hydrate]

2) $\mathrm{NbPMo}_{12} \mathrm{O}_{40}$ [Niobium exchanged phosphomolybdic acid]

3) $\mathrm{PMo}_{12} \mathrm{O}_{40} \mathrm{pyr}$ [Pyridine exchanged phosphomolybdic acid]

4) $\mathrm{NbPMo}_{12} \mathrm{O}_{40}$ pyr [Niobium and pyridine exchanged phosphomolybdic acid]

Previously the above catalysts were studies by Holles et al., for the selective oxidation of n-butane. In the previous work, it was found that the catalyst with the combination of niobium and pyridine was the most active and had high selectivity [1]. These studies were done to see how the selectivity and reactivity of the catalysts changed with the addition of niobium and pyridine. $\mathrm{Li}$ and Ueda showed that treating $\mathrm{H}_{3} \mathrm{PMo}_{12} \mathrm{O}_{40}$ catalyst with pyridine and then activating in nitrogen at $420^{\circ} \mathrm{C}$ improved the activity for the selective oxidation of propane to acrylic acid [16].

\subsection{Microcalorimetry}

The surface acid and base sites distributions on oxide surfaces can be determined through microcalorimetric studies [17-20]. Microcalorimetry studies help in determining the strength of the acidic sites exposed on the solid surface of the catalyst. The distribution of these sites is necessary to understand the catalytic properties. The conversion and selectivity of a reaction are influenced by the nature of the active sites, their number and also their strength. Auroux and Gervasini have reported the study of acidity and basicity on metal oxides surfaces[9] and have used microcalorimetry in order to determine the 
number and character of basic and acidic surface sites. Several other papers have also studied the acidity of heteropolycomponents using ammonia absorption[10, 15, 21, 22].

Previously, methods such as titration with Hammett indicators, temperature-programmed desorption, adsorption microcalorimetry, catalytic probe reactions and NMR spectroscopy were used to determine the solid acids for the strength and number of sites[23]. Interactions with acid sites in solids are usually studied with ammonia because it is one of the simplest molecules and is also the most studied basic probe molecule[15]. Strong acids bind more strongly with ammonia than weaker acids. The choice of the base probe molecule is important in order to aptly characterize the surface. Ammonia is used because it is a small molecule and has affinity to base catalysts and most of the acid sites can be detected by ammonia $[9,10]$.

The calorimetric determination of heats of adsorption of bases produces curves of the type of differential heat of adsorption as a function of amount adsorbed, from which the distribution of adsorption sites over adsorption energies can be obtained[24]. This information gives details of the concentration of acid sites with different strengths in catalysts and also for identifying the relation between acidity and activity of different catalytic reactions[24]. In this study, chemisorption is of interest and is an essential step in heterogenous catalysis, therefore, the bonding strength between the adsorbate and surface is an important parameter[25]. The activation energy of the surface reaction and also the surface concentration of the reactants can be affected depending on the strength of the chemisorptions bond[25]. Therefore the determination of the heats of adsorption of 
gas-phase molecules on strong active sites is of importance and it should also be noted that the values of heat of adsorption can indicate not only the strength of the interaction on the surface of the catalyst but also the properties on it [25].

Previously, Bardin et al have reported the heat of ammonia adsorption for $\mathrm{H}_{3} \mathrm{PMO}_{12} \mathrm{O}_{40}$ catalyst to be around $100 \mathrm{KJ} / \mathrm{mol}$ at $573 \mathrm{~K}$ and $120 \mathrm{KJ} / \mathrm{mol}$ at $473 \mathrm{~K}$. They had very few sites at $573 \mathrm{~K}$ and ammonia uptake of about $200(\mu \mathrm{mol} / \mathrm{g})$. But when the temperature was decreased to $473 \mathrm{~K}$, they ended up having more number of sites and higher ammonia uptake of above $1000(\mu \mathrm{mol} / \mathrm{g})$. This shows that the strength of the sites was high at 473K[10]. Jozefowicz et al have shown that $\mathrm{H}_{3} \mathrm{PMO}_{12} \mathrm{O}_{40}$ activated at $423 \mathrm{~K}$ had initial heat of adsorption of about $200 \mathrm{KJ} / \mathrm{mol}$ and at $523 \mathrm{~K}$ the heat of adsorption dropped to $150 \mathrm{KJ} / \mathrm{mol}[26]$. Lapkin et al have also shown similar result for the heat of adsorption for $\mathrm{H}_{3} \mathrm{PMO}_{12} \mathrm{O}_{40}[27]$. It can be noted that as pretreatment temperature increases, the initial heat of adsorption decreases. The strength of the sites also decreases with increase in temperature.

Jin et al have shown that the heat of adsorption of $\mathrm{Nb}_{2} \mathrm{O}_{5}$ at $373 \mathrm{~K}$ was $80 \mathrm{KJ} / \mathrm{mol}[28]$. But, recently Sun et al have reported that the ammonia adsorption at $423 \mathrm{~K}$ for $\mathrm{Nb}_{2} \mathrm{O}_{5}$ had an initial heat of adsorption of $150 \mathrm{KJ} / \mathrm{mol}$ with an ammonia uptake of about 280 $(\mu \mathrm{mol} / \mathrm{g})[29]$. Interestingly, Petre et al did not find any change in the heat of adsorption for $\mathrm{Nb}_{2} \mathrm{O}_{5}$ at $353 \mathrm{~K}$ and $423 \mathrm{~K}$; at both the temperatures it was at $125 \mathrm{KJ} / \mathrm{mol}[30]$. Xue et al have reported the heat of adsorption of $\mathrm{MoO}_{3}$ to be as low as $20 \mathrm{KJ} / \mathrm{mol}$ with an ammonia uptake of $125(\mu \mathrm{mol} / \mathrm{g})[31]$. Bardin et al have performed acidity of keggin type 
heteropolycompounds by a number of methods including ammonia adsorption microcalorimetry[10,15]. Xie et al shows the use of microcalorimetry to investigate the acid site distribution on carbons[21].

\subsection{Methanol Oxidation}

Work of Holles et al, Ueda and Suzuki showed that a molybdovanadophosphoric acid $\left(\mathrm{PMo}_{11} \mathrm{~V}\right)$ when treated with pyridine results in an active and selective catalyst for the conversion for propane to acrylic acid[1,32]. Later, Li and Ueda showed that when pyridine is added to molybdophosphoric acid $\left(\mathrm{H}_{3} \mathrm{PMo}_{12}\right)$ and heated to $420^{\circ} \mathrm{C}$ to activate the catalyst in presence of nitrogen, it improved the activity for the selective oxidation of propane to acrylic acid[1, 16]. By preheating the catalyst sample to $420^{\circ} \mathrm{C}$ all the organic components from the catalysts precursors are removed [14]. It also helps in finding out if the catalyst holds on to its properties at high temperature or if there is any change in it.

Methanol oxidation has been recognized as a dependable chemical probe of metal oxide catalysts through comparison of the catalytic activity and product selectivity[33]. To study the surface metal oxide redox sites, the reactivity of oxidative catalysts can be done by methanol oxidation reaction [34-38]. Methanol oxidation as discussed in the review of Tatibouët [33] refers to the network of oxidation and dehydration reactions. The reason for choosing methanol as the probe molecule to determine the number of surface active sites on pure metal oxides is due to the commonality of the surface methoxy intermediate formed during dissociative chemisorptions of methanol and methanol oxidation on the oxide catalysts [8]. In addition, methanol has high reactivity towards metal oxides [8]. 
Methanol oxidation reactions on metal oxide surfaces are very sensitive to the nature of active catalytic sites[33]. Methanol molecules are initially adsorbed on the surface metal sites as methoxy $\left(\mathrm{CH}_{3} \mathrm{O}\right)$ species during the partial oxidation of methanol [34-39]. The products formed after the methanol oxidation reactions are formaldehyde, methylformate, dimethoxymethane, dimethyl ether and carbon oxides. The product distribution is determined by the nature of the surface active sites [3].The dehydration product yields the acid sites, that is dimethyl ether. The carbon oxides in the catalyst yield basic sites. The redox sites yield formaldehyde, methylformate and dimethoxymethane.

The knowledge of the number of surface active sites enables the calculation of the catalytic activity during methanol oxidation. The acid, base and redox properties of the products formed after methanol oxidation reaction can be analyzed for a range of pure metal oxides catalysts. These findings will help in better understanding of the catalysts and hopefully provide new insight into the fundamental catalytic properties of pure metal oxides.

Previous methanol oxidation studies have been carried out on molybdenum oxide catalysts, niobium oxide catalysts, vanadium oxide catalysts and other oxides by Wachs et al $[3,34,40]$. They have shown that $\mathrm{MoO}_{3}$ had more selectivity for redox than acid product, $\mathrm{Nb}_{2} \mathrm{O}_{5}$ had only acidic product selectivity and $\mathrm{V}_{2} \mathrm{O}_{5}$ had very high selectivity for redox product compared with that of acidic product $[3,34,40]$. 


\subsection{Aims/Goals of thesis:}

The aim of this study is to show how the two distinct aspects of selective oxidation, acid/base strength and redox properties, contribute to the high activity of the heteropolyacids when niobium and pyridine are added on to them. Also to better understand the acid, base and redox properties of the catalysts. The catalyst we used are phosphomolybdic acid $\left(\mathrm{H}_{3} \mathrm{PMo}_{12} \mathrm{O}_{40}\right)$, pyridine exchanged phosphomolyblic acid $\left(\mathrm{PMo}_{12} \mathrm{O}_{40}\right.$ pyr), niobium exchanged phosphomolybdic acid $\left(\mathrm{NbPMo}_{12} \mathrm{O}_{40}\right)$ and niobium and pyridine exchanged phosphomolybdic acid $\left(\mathrm{NbPMo}_{12} \mathrm{O}_{40} \mathrm{pyr}\right)$ catalysts. Here the methods used to study the properties of these catalysts are ammonia adsorption microcalorimetry (acid/base aspect) and methanol oxidation reaction (redox aspect).

In the present work, we report how the introductions of niobium and pyridine on the parent catalyst, $\mathrm{H}_{3} \mathrm{PMo}_{12} \mathrm{O}_{40}$, have an effect in the heat of adsorption of the catalysts by ammonia adsorption microcalorimetry. We further discuss about the nature of active sites present on the catalyst surface through product distribution. This is done by methanol oxidation reaction, which gives information about the acid, base and redox sites of the catalyst surface. The effect of metal oxides on the selectivity and strength of the catalyst can be found. This helps in better understanding of the polyoxometalate catalysts. The activity of the catalysts is also discussed during methanol oxidation.

The results obtained from our study are compared to the results obtained from other literature, carried out using the same methods to study the properties of other similar catalysts. Some authors have used the same catalysts but different probe molecule and 
other authors have used the metal oxides in their study. Nevertheless, comparing the data with other literature helps in identifying efficient catalysts for industrial use and also to better understand the fundamental properties of the catalysts. 


\section{Chapter 2}

\section{Catalyst Preparations}

\section{1) $\mathrm{H}_{3} \mathrm{PMo}_{12} \mathrm{O}_{40}$}

Phosphomolybdic acid hydrate $\left(\mathrm{H}_{3} \mathrm{PMo}_{12} \mathrm{O}_{40}\right)$ was purchased from Aldrich and used directly.

\section{2) $\mathrm{NbPMo}_{12} \mathrm{O}_{40}$}

Niobium exchanged phosphomolybdic acid $\left(\mathrm{NbPMo}_{12} \mathrm{O}_{40}\right)$ catalyst was prepared by using a known method from literature [1]. Niobium pentachloride $\left(\mathrm{Nb} \mathrm{Cl}_{5}\right)$ was purchased from Aldrich. The solution of Niobium pentachloride $(0.3025 \mathrm{~g})$ and water (2.5mL) was basified with ammonium hydroxide $(0.125 \mathrm{~mL})$. The white precipitate formed was then removed by filtration and the product was dissolved in an aqueous oxalic acid $(0.252 \mathrm{~g}$ in $5 \mathrm{~mL}$ water) to form niobium oxalate solution. The niobium oxalate solution was then added slowly to $\mathrm{H}_{3} \mathrm{PMo}_{12} \mathrm{O}_{40}(5 \mathrm{~g})$ dissolved in water $(10 \mathrm{~mL})$. The liquid was then evaporated completely by heating and stirring the mixture continuously.

\section{3) $\mathrm{PMo}_{12} \mathrm{O}_{40}$ pyr}

Pyridine exchanged phosphomolyblic acid $\left(\mathrm{PMo}_{12} \mathrm{O}_{40}\right.$ pyr) catalyst was prepared by first dissolving phosphomolybdic acid hydrate $\left(\mathrm{H}_{3} \mathrm{PMo}_{12} \mathrm{O}_{40}\right)(3 \mathrm{~g})$ in water and then adding an aqueous solution of pyridine $(0.4205 \mathrm{~mL}$ in $2.5 \mathrm{~mL}$ water $)$ to the solution. The liquid was then evaporated completely by heating and stirring the mixture continuously[1]. 
4) $\mathrm{NbPMo}_{12} \mathrm{O}_{40} \mathrm{pyr}$

Similar procedure was used to prepare niobium and pyridine exchanged phosphomolybdic acid ( $\mathrm{NbPMo}_{12} \mathrm{O}_{40}$ pyr) catalyst. Niobium exchanged phosphomolybdic acid $\left(\mathrm{NbPMo}_{12} \mathrm{O}_{40}\right)$ catalyst was prepared by the method shown above. The obtained niobium exchanged phosphomolybdic acid $\left(\mathrm{NbPMo}_{12} \mathrm{O}_{40}\right)(2 \mathrm{~g})$ was dissolved in water. To this solution an aqueous solution of pyridine $(0.252 \mathrm{~mL}$ in $2.5 \mathrm{ml}$ water $)$ was added. The liquid was then evaporated by heating and stirring the mixture continuously.[1]

\subsection{Experimental Setup}

The equipments used for the experiment consisted of gas and liquid units such as gas cylinders, mass flow controllers, methanol bubbler, reactor and GC/MS as shown in figure (2-1). The reactor setup consisted of a methanol bubbler, digital flow rate controller (Omega), a packed bed reactor and a GCMS (Finnegan, Trace GC ultra, Trace DSQ, Thermo Electron Corporation). The digital flow rate controller was used to control the flowrate of helium and oxygen gaseous mixture that is flowed through the methanol bubbler. The catalysts were placed in a glass tube of $6 \mathrm{~mm}$ and were supported by glass wool. The reactor was a downflow reactor operating at atmospheric pressure. The reactant flow was a single pass. Each catalyst sample run was pretreated to $420^{\circ} \mathrm{C}$ for 6 hours and held at the same temperature for 4 hours and then cooled to $260^{\circ} \mathrm{C}$ in 1 hour in presence of helium flow. Feed gases consisted of helium compressed (UN 1046, 5.0 ultra high purity, (UHP)) and oxygen compressed (UN 1072). The effluent from the reactor was connected to the GC/MS were the analysis was done. 


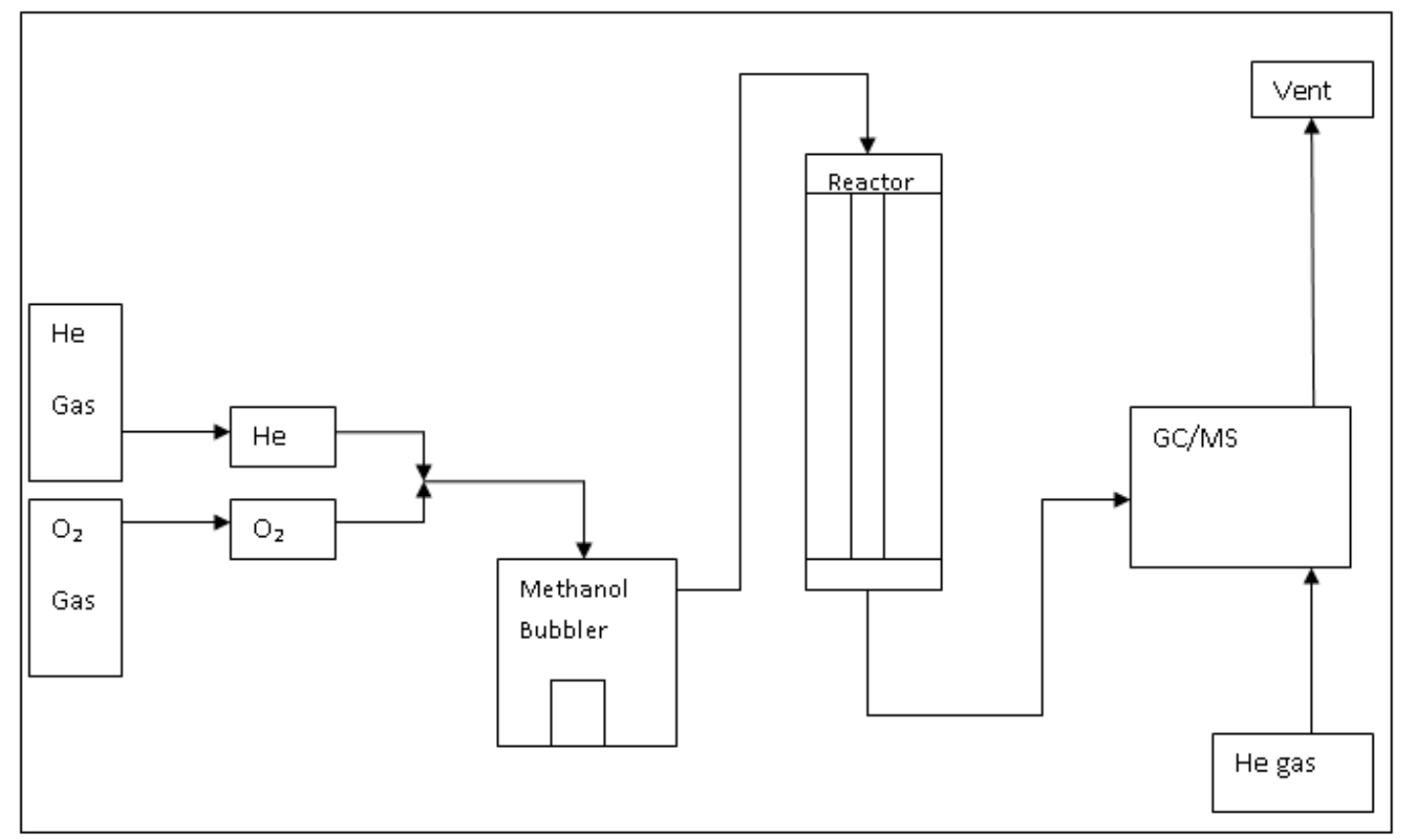

Figure (2-1): Experimental Setup

\subsection{Mass flow controller calibration:}

Digital flow rate controllers (Omega, model-FMA 78P4) were used to control the gas flow rates to the methanol bubbler. The flow controllers were calibrated using a glass bubble flow meter operating at room temperature and atmospheric pressure. The calibration results are plotted in figures (2-2) and (2-3) for helium and oxygen mass flow controllers respectively. These controllers enabled precise control of reactant concentrations and flow rates. To maintain low conversion, about $\sim 10 \%$, flow rates were changed for each catalyst during methanol oxidation. 


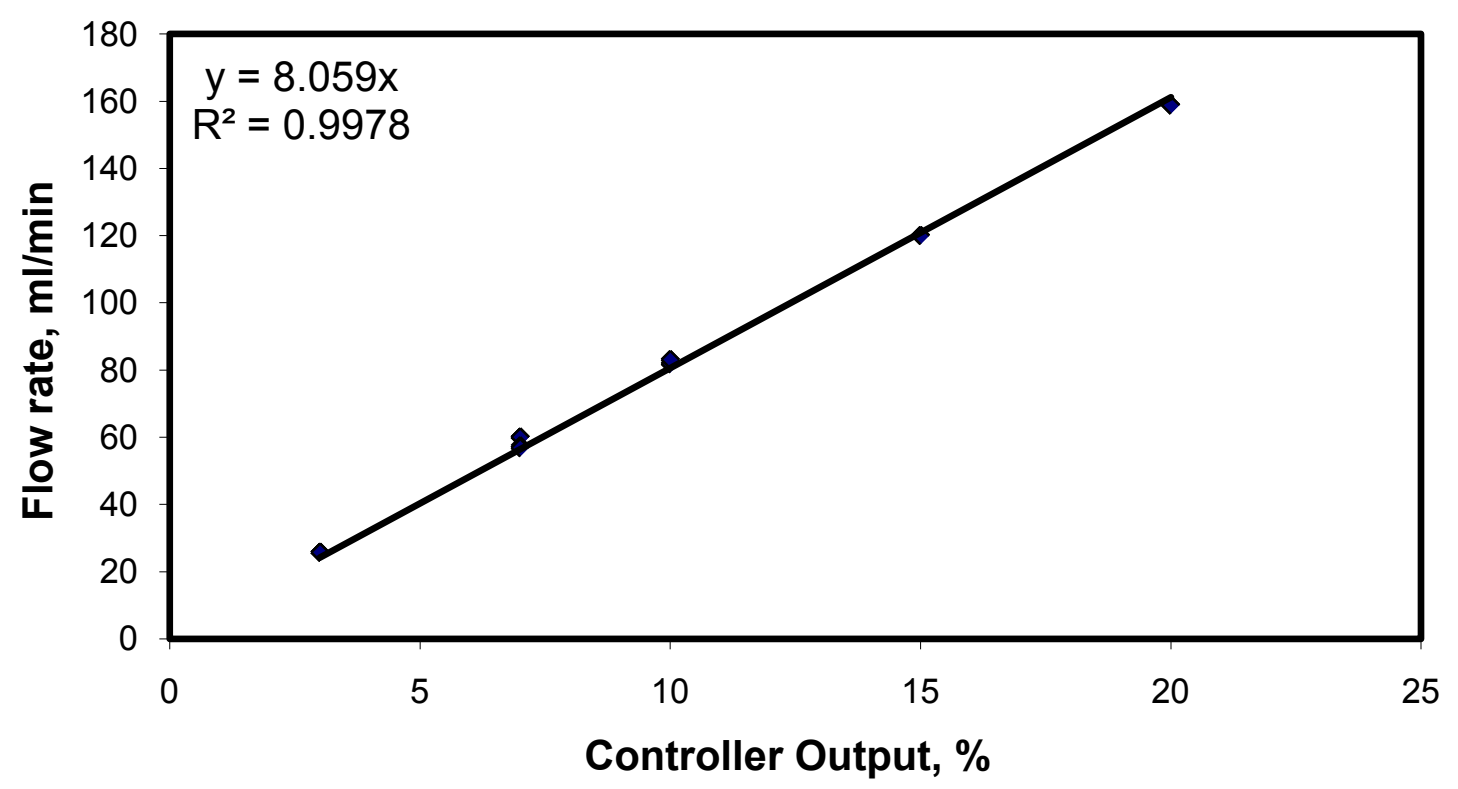

Figure (2-2): Helium Mass Flow Controller Calibration Results

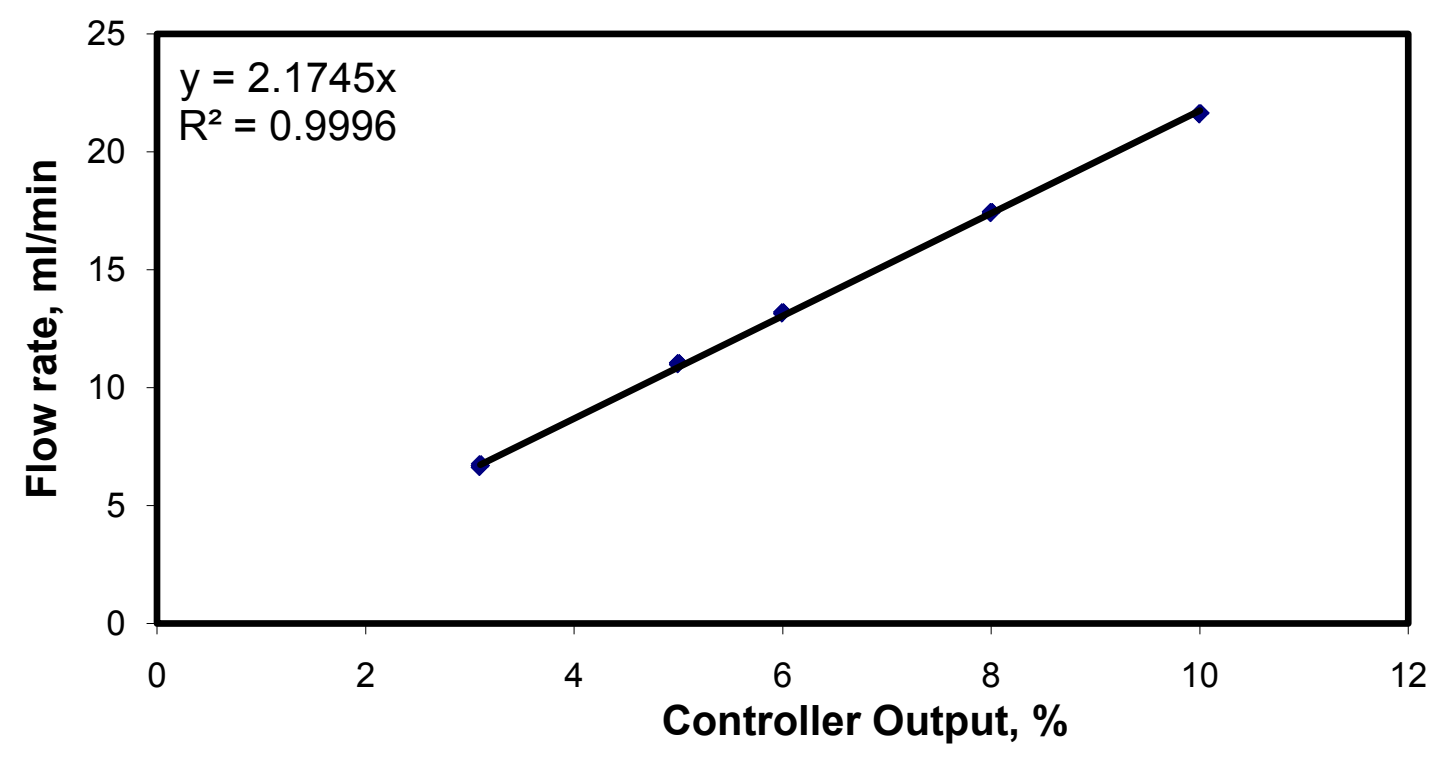

Figure (2-3): Oxygen Mass Flow Controller Calibration Results 


\subsection{GC/MS description and Setup}

The GC/MS used was Finnegan, Trace GC ultra, Trace DSQ, Thermo Electron Corporation. The column used in the GC/MS was Equity ${ }_{-1}^{\mathrm{TM}}$, fused silica capillary column $(30 \mathrm{~m} * 0.25 \mathrm{~mm} * 0.25 \mu \mathrm{m}$ film thickness $)$. The column temperature was maintained at $50^{\circ} \mathrm{C}$ throughout the entire analysis.

\subsection{Run procedure: Methanol Oxidation}

The reactivity of supported phosphomolybdic acid derived catalysts was probed by the methanol oxidation reaction. The reactor setup consisted of a methanol bubbler, digital flow rate controller (Omega), a packed bed reactor and a GCMS (Finnegan, Trace GC ultra, Trace DSQ, Thermo Electron Corporation). The digital flow rate controller was used to control the flow rate of helium and oxygen gaseous mixture that is flowed through the methanol bubbler. The catalysts were placed in a glass tube of $6 \mathrm{~mm}$ and were supported by glass wool. The reactor was a downflow reactor operating at atmospheric pressure. The reactant flow was a single pass. Each catalyst sample run was pretreated to $420^{\circ} \mathrm{C}$ for 6 hours and held at the same temperature for 4 hours and then cooled to $260^{\circ} \mathrm{C}$ in 1 hour in presence of helium flow. This treatment is consistent with pretreatment procedures of this catalyst from the literature [17].

The methanol bubbler was connected to the reactor and the outlet from the reactor was connected to the GC. The outlet connected to the $\mathrm{GC}$ was heated to $100^{\circ} \mathrm{C}$, so that any condensation of the products in the line can be avoided and also to remove traces of water formed during the reaction. Feed gases consisted of helium compressed (UN 1046, 5.0 
ultra-high purity, (UHP)) and oxygen compressed (UN 1072). Initially oxygen and helium with the required flowrate is bubbled through methanol in the bubbler and run without the catalyst in the glass tube, so as to obtain the methanol count. Molar feed ratio into the GCMS taken was mixture of $\mathrm{He} / \mathrm{O}_{2} / \mathrm{MeOH}$ at the ratio 5.6:1:1.3, the reaction was run at a standard temperature of $260^{\circ} \mathrm{C}$ for all the catalysts, the flowrates of helium and oxygen modified as required and the catalyst weight $(0.01 \mathrm{gm}$ to $0.04 \mathrm{gm})$ was taken to obtain around $10 \%$ methanol conversion. Once feed was initiated to the reactor, the catalytic runs were taken for 2-3 hours with samples at an interval of 4 min, beginning 10 min after the methanol flow to the reactor was initiated. Product analysis was done by using the GCMS (Finnegan, Trace GC ultra, Trace DSQ, Thermo Electron Corporation)

with a Equity ${ }^{\mathrm{TM}}-1$,fused silica capillary column $(30 \mathrm{~m} * 0.25 \mathrm{~mm} * 0.25 \mu \mathrm{m}$ film thickness). The selectivity of the products is defined in mole percentages.

\subsection{GCMS Calibration:}

Calibration of the GC/MS was done for the feed methanol and all the products of interest. The main by-products of the catalysts under study from methanol oxidation were dimethoxymethane, dimethyl ether and formaldehyde. From these calibrations the GC/MS counts can be converted to moles of each product. Determination of the number of moles of each product formed allows calculation of reaction rate and selectivity. The calibration of the GC/MS for methanol feed and each product is shown in the figures (24), (2-5), (2-6) and (2-7).

Methanol, formaldehyde and dimethoxymethane liquids were calibrated using a bubbler with helium carrier to produce a saturated vapor. The vapor pressure was calculated to 
determine the gas phase concentration of each component sent into the GC/MS. Because of this technique single point calibration was necessary.

Methanol was calibrated using the GC/MS. Pure methanol was bubbled by using helium carrier gas and the concentration in the gas phase was determined by the vapor pressure calculations. Peak curves from the GC/MS was averaged and plotted as a single point graph. Starting a point at zero was used so that we could establish a linear calibration curve from methanol readings. Similar procedure was used for formaldehyde and dimethoxymethane.

Analysis of formaldehyde gave multi components and it was not possible to find the concentration of formaldehyde. So for formaldehyde, we used methanol calibration to back calculate the formaldehyde concentration in order to establish formaldehyde calibration curve.

Concentration of dimethyl ether was varied using helium gas to establish different concentrations in gas phase. The readings were carried out directly in the GC/MS. 


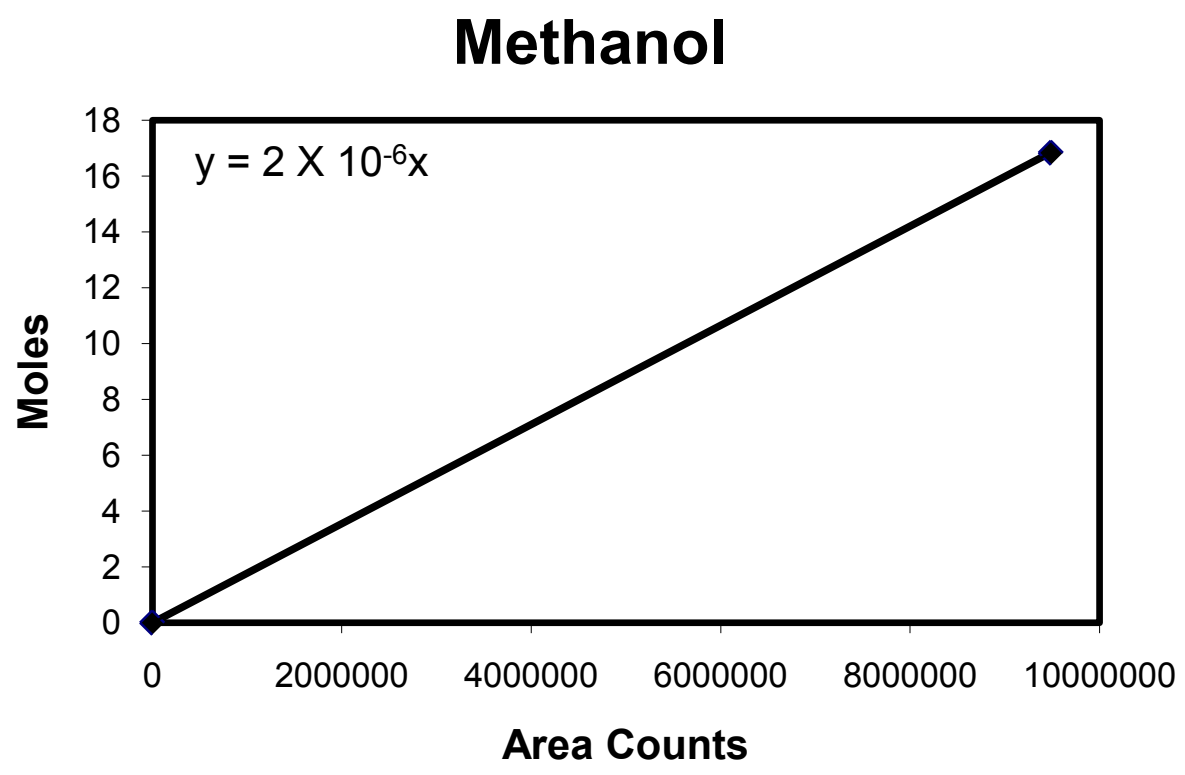

Figure (2-4): Calibration Curve for Methanol (GC/MS)

\section{Formaldehyde}

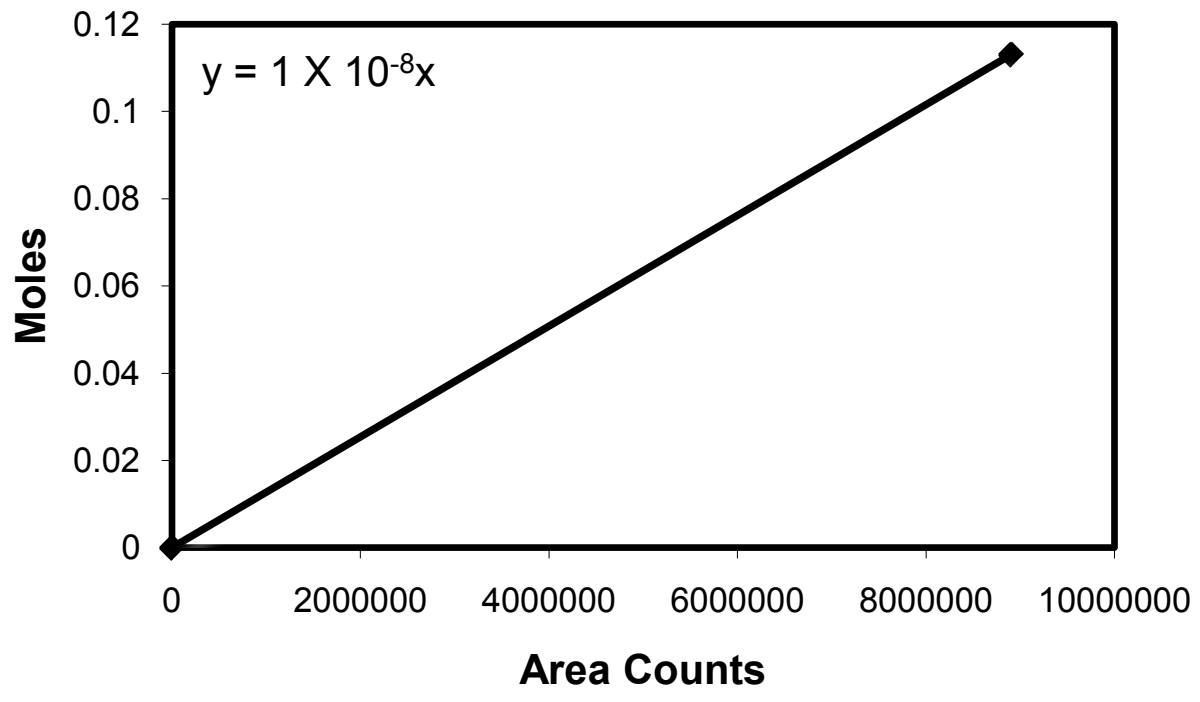

Figure (2-5): Calibration Curve for Formaldehyde (GC/MS) 


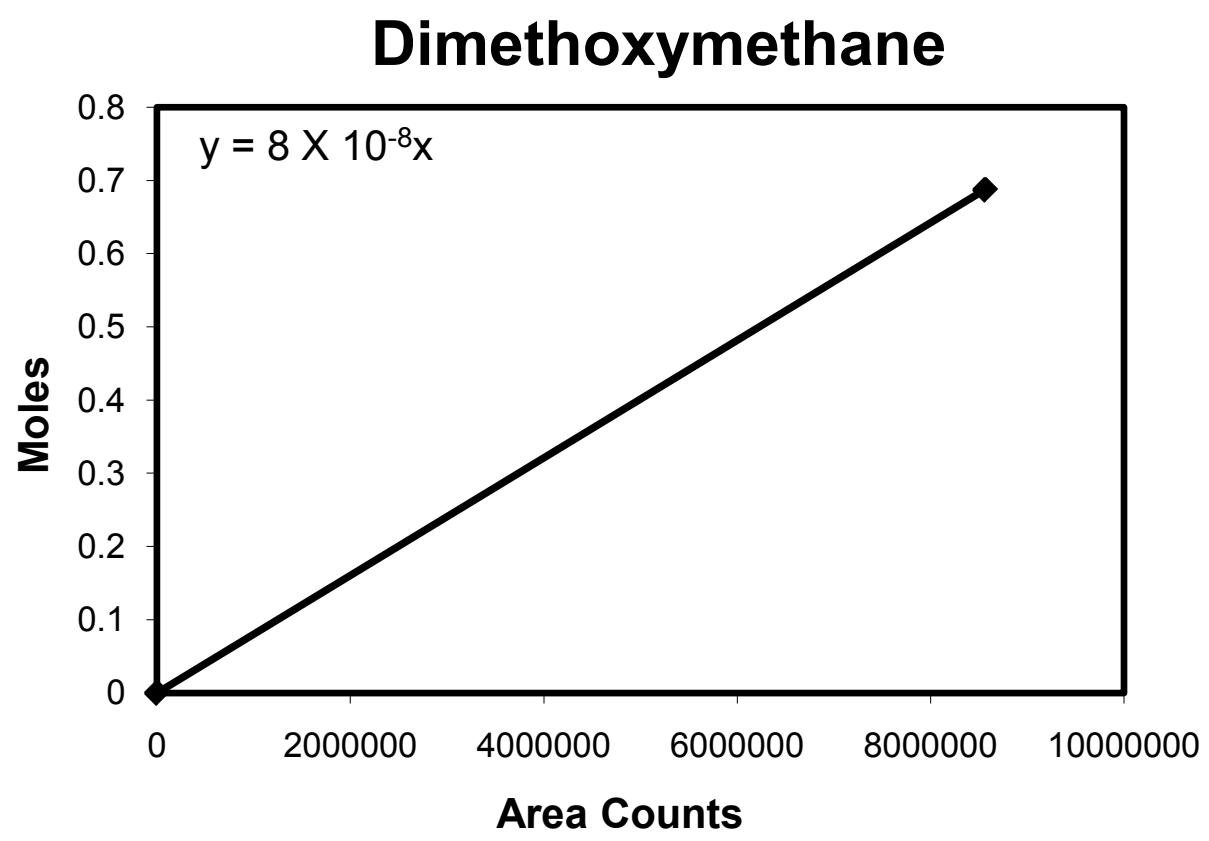

Figure (2-6): Calibration Curve for Dimethoxymethane (GC/MS)

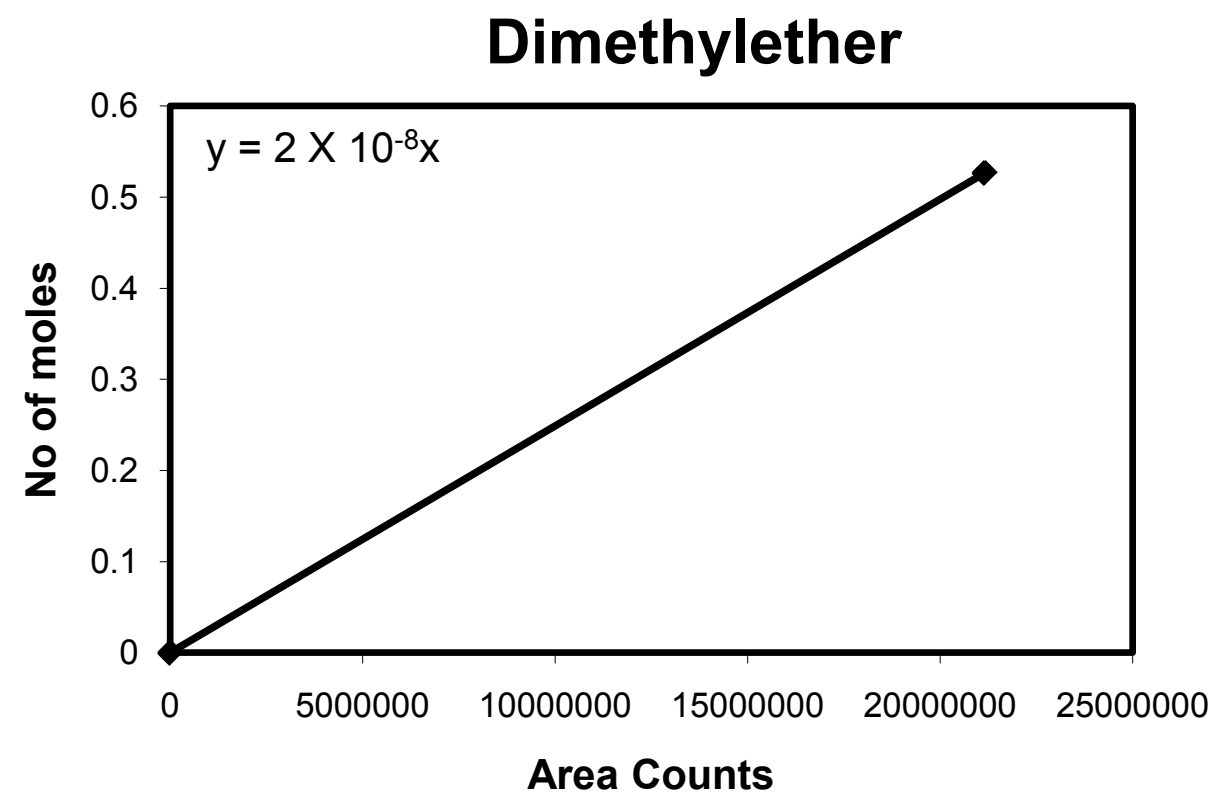

Figure (2-7): Calibration Curve for Dimethyl Ether (GC/MS) 


\subsection{Microcalorimetry}

This work was carried out by Eric J. Doskocil, Department of Chemical Engineering, University of Missouri.

The microcalorimetry studies was carried out in an International Thermal Instruments block in a home built system and all the catalyst samples where pretreated at $420^{\circ} \mathrm{C}$ under vacuum. Pure ammonia was used as the adsorbate and ammonia adsorption was carried out at room temperature.

\subsection{Reaction rate calculation}

The rate of each catalyst was calculated as the (concentration of methanol * flowrate of the no of moles $*$ conversion of methanol $*$ selectivity of each product) divided by the (weight of each catalyst taken * the surface area of each catalyst).

\subsection{Selectivity calculations}

The selectivity of each product was carried by using the GC/MS calibration plots from figures (2-5), (2-6) and (2-7). From the plot the number of moles of the individual

product was obtained after the reaction. The selectivity (\%) was calculated as the (number of moles converted to a product)/(total no of moles of all the products formed). 


\subsection{Surface Area Measurements}

The BET surface area analysis of the catalysts under study was determined by nitrogen adsorption isotherms on a Micromeritics surface area and porosity analyzer, (Micromertitics, model ASAP 2020) using nitrogen as the carrier gas. Around $0.1 \mathrm{~g}$ of each sample was used for the measurement and the sample was pretreated at $420^{\circ} \mathrm{C}$ prior to nitrogen adsorption. 


\section{Chapter 3}

\section{Characterization of Partially Reduced Polyoxometalate Catalysts Using Ammonia Adsorption Microcalorimetry and Methanol Oxidation Studies}

\subsection{Introduction}

Heteropolyacids (HPA's) are commonly known as strong acid catalysts both in liquid and solid forms[12]. A variety of uses for these catalysts has been discussed in a volume of chemical reviews[14]. Selective oxidation studies are extensively carried out on light hydrocarbons or alkanes like ethane, propane and butane[4], to obtain products such as acrylic acid and maleic acid since these reactants are readily available and inexpensive[1]. At present in chemical industries, the selective oxidation of hydrocarbon reactions continue to play an important role resulting in ongoing investigation of the heterogeneous catalysts that accomplish these reactions. The reason that the hetero poly acid catalysts and their salts are usually investigated for their ability to perform selective oxidation reactions is because of their structure and composition can be finely controlled. One of the major challenges is to determine the surface active sites on the metal oxides to understand the fundamental catalytic relationships for metal oxide catalysts[8].The nature of active sites, their number and their strength on the catalyst surface determines the selectivity and conversion capabilities of the catalyst. The nature of the oxide, the charge and the radius of the metal ions will have an effect on the acidity and basicity of the catalyst[9]. 
Auroux and Gervasini have carried out a thermodynamic scale of surface acidity and basicity in which they determine the acid and base properties by measuring the heat of absorption and adsorption uptake of gas -phase molecules on a number of simple metal oxides[9]. The choice of the base probe molecule is important in order to aptly characterize the surface and ammonia was used because it is a small molecule and has affinity to base catalysts and most of the acid sites can be detected by ammonia[9, 10$]$. Bardin et al have performed acidity measurements of keggin type heteropolycompounds by a number of methods including ammonia adsorption microcalorimetry[10, 15]. Xie et al shows the use of microcalorimetry to investigate the acid site distribution on carbons[21].

Phosphomolybdic acid hydrate $\left(\mathrm{H}_{3} \mathrm{PMo}_{12} \mathrm{O}_{40}\right)$ consists of the Keggin structure which is commonly associated with heteropolyacids (HPAs) that have specific molecular architectures having metal-oxygen cluster compounds [14, 41]. The heterpolyoxomolybdates catalysts having the Keggin type structure are active for partial oxidation of alkenes and alkanes [1, 42-45]. The bifunctional nature of the heteroployacids and their polyoxometalate as both acid and oxidation catalysts have made them effective in many different catalytic applications[1]. Especially, polyoxometalates and phosphomolybdates have been extensively investigated for the selective oxidation of light alkanes [5-7]. 
To study the surface metal oxide redox sites the reactivity of oxidative catalysts can be done by methanol oxidation reaction[34-38]. Previous methanol oxidation studies have been carried out on extensive number of oxides such as molybdenum oxide catalysts and vanadium oxide catalysts by Wachs and colleagues[3, 34, 40]. Methanol oxidation as referred in the review of Tatibouett[33] refers to the network of oxidation and dehydration reactions. Methanol has high reactivity towards metal oxides and has a commonality to the surface methoxy intermediate formed during the methanol oxidation and dissociative chemisorption of methanol on oxide catalysts [8]. Methanol molecules are initially adsorbed on the surface molybdenum sites as methoxy $\left(\mathrm{CH}_{3} \mathrm{O}\right)$ species during the partial oxidation of methanol [34-39]. The products formed after the methanol oxidation are formaldehyde, methylformate, dimethoxymethane, dimethyl ether and carbon oxides. The product distribution is determined by the nature of the surface active sites [3].The dehydration product yields the acid sites dimethyl ether, carbon oxides yield basic sites and the redox sites yield formaldehyde, methylformate and dimethoxymethane.

Work of Ueda and Suzuki showed that a molybdovanadophosphoric acid $\left(\mathrm{PMo}_{11} \mathrm{~V}\right)$ when treated with pyridine result is an active and selective catalyst for the conversion for propane to acrylic acid[1,32] and later Li and Ueda showed that when pyridine is added to molybdophosphoric acid $\left(\mathrm{H}_{3} \mathrm{PMo}_{12}\right)$ and heating to $420^{\circ} \mathrm{C}$ to activate in presence of nitrogen, improved the activity for the selective oxidation of propane to acrylic acid $[1,16]$. By preheating the catalyst sample to $420^{\circ} \mathrm{C}$ all the organic components from the catalysts precursors or removed [14]. Niobium and pyridine-exchanged 
molybdophospheric and molybovanadophospheric acid catalysts $\left(\mathrm{NbPMo}_{12} \mathrm{pyr}\right.$ and $\mathrm{NbPMo}_{11} \mathrm{Vpyr}$ ) for selective oxidation of propane and butane was reported by Holles et $\operatorname{al}[1,44]$

In this paper we report how the introductions of niobium and pyridine on the parent catalyst $\mathrm{H}_{3} \mathrm{PMo}_{12} \mathrm{O}_{40}$ have an effect on the heat of adsorption of the catalysts as determined by ammonia adsorption microcalorimetry. In addition, the methanol oxidation reaction is used to obtain information about the acid, base and redox sites of the catalyst surface. The aim of this paper is to show how the activities of the heteropolyacid catalysts are effected when niobium and pyridine are added to them and also to better understand the acid, base and redox properties of the catalysts.

\subsection{Experimental: Catalyst preparation}

1) $\mathrm{H}_{3} \mathrm{PMo}_{12} \mathrm{O}_{40}$

Phosphomolybdic acid hydrate $\left(\mathrm{H}_{3} \mathrm{PMo}_{12} \mathrm{O}_{40}\right)$ was purchased from Aldrich and used directly.

2) $\mathrm{NbPMo}_{12} \mathrm{O}_{40}$

Niobium exchanged phosphomolybdic acid $\left(\mathrm{NbPMo}_{12} \mathrm{O}_{40}\right)$ catalyst was prepared by using a known method from literature[1]. Niobium pentachloride $\left(\mathrm{NbCl}_{5}\right)$ was purchased from Aldrich. The solution of Niobium pentachloride $(0.3025 \mathrm{~g})$ and water $(2.5 \mathrm{~mL})$ was basified with ammonium hydroxide $(0.125 \mathrm{~mL})$. The white precipitate formed was then 
removed by filtration and the product was dissolved in an aqueous oxalic acid $(0.252 \mathrm{~g}$ in $5 \mathrm{~mL}$ water) to form niobium oxalate solution. The niobium oxalate solution was then added slowly to $\mathrm{H}_{3} \mathrm{PMo}_{12} \mathrm{O}_{40}(5 \mathrm{~g})$ dissolved in water $(10 \mathrm{~mL})$. The liquid was then evaporated completely by heating to $80^{\circ} \mathrm{C}$ and stirring the mixture continuously.

\section{3) $\mathrm{PMo}_{12} \mathrm{O}_{40} \mathrm{pyr}$}

Pyridine exchanged phosphomolybic acid $\left(\mathrm{PMo}_{12} \mathrm{O}_{40}\right.$ pyr) catalyst was prepared by first dissolving phosphomolybdic acid hydrate $\left(\mathrm{H}_{3} \mathrm{PMo}_{12} \mathrm{O}_{40}\right)(3 \mathrm{~g})$ in water and then adding an aqueous solution of pyridine $(0.4205 \mathrm{~mL}$ in $2.5 \mathrm{~mL}$ water $)$ to the solution. The liquid was then evaporated completely by heating to $80^{\circ} \mathrm{C}$ and stirring the mixture continuously[1].

4) $\mathrm{NbPMo}_{12} \mathrm{O}_{40} \mathrm{pyr}$

Similar procedure was used to prepare niobium and pyridine exchanged phosphomolybdic acid $\left(\mathrm{NbPMo}_{12} \mathrm{O}_{40} \mathrm{pyr}\right)$ catalyst. Once niobium exchanged phosphomolybdic acid $\left(\mathrm{NbPMo}_{12} \mathrm{O}_{40}\right)$ catalyst was prepared by the method shown above, $(2 \mathrm{~g})$ was dissolved in water. To this solution an aqueous solution of pyridine $(0.252 \mathrm{~mL}$ in $2.5 \mathrm{ml}$ water) was added. The liquid was then evaporated by heating to $80^{\circ} \mathrm{C}$ and stirring the mixture continuously.[1]

\subsection{BET Surface Area Analysis:}

The BET surface area analysis of the above catalysts was determined by nitrogen adsorption isotherms on a Micromeritics surface area and porosity analyzer, 
(Micromeritics, model ASAP 2020) using nitrogen as the carrier gas. Around $0.1 \mathrm{~g}$ of each sample was used for the measurement and the sample was pretreated at $420^{\circ} \mathrm{C}$ prior to nitrogen adsorption.

\subsection{Methanol Oxidation reactions:}

The reactivity of supported phosphomolybdic acid derived catalysts was probed by the methanol oxidation reaction. The reactor setup consisted of a methanol bubbler, digital flow rate controller (Omega), a packed bed reactor and a GCMS (Finnegan, Trace GC ultra, Trace DSQ, Thermo Electron Corporation). The digital flow rate controller was used to control the flowrate of helium and oxygen gaseous mixture that is flowed through the methanol bubbler. The catalysts were placed in a glass tube of $6 \mathrm{~mm}$ and were supported by glass wool. The reactor was a downflow reactor operating at atmospheric pressure. The reactant flow was a single pass. Each catalyst sample run was pretreated to $420^{\circ} \mathrm{C}$ for 6 hours and held at the same temperature for 4 hours and then cooled to $260^{\circ} \mathrm{C}$ in 1 hour in presence of helium flow.

Feed gases consisted of helium compressed (UN 1046, 5.0 ultra high purity, (UHP)) and oxygen compressed (UN 1072). Molar feed ratio into the GCMS taken was mixture of $\mathrm{He} / \mathrm{O}_{2} / \mathrm{MeOH}$ at the ratio 5.6:1:1.3, the reaction was run at a standard temperature of $260^{\circ} \mathrm{C}$ for all the catalysts, the flowrates of helium and oxygen modified as required and the catalyst weight $(0.01 \mathrm{gm}$ to $0.04 \mathrm{gm})$ was taken to obtain around $10 \%$ methanol conversion, so that complications due to heat and mass transfer limitations can be 
avoided [3]. Once feed was initiated to the reactor, the catalytic runs were taken for 2-3 hours with samples at an interval of $4 \mathrm{~min}$, beginning $10 \mathrm{~min}$ after the methanol flow to the reactor was initiated. Product analysis was done by using the GCMS (Finnegan, Trace GC ultra, Trace DSQ, Thermo Electron Corporation) with a Equity ${ }^{\mathrm{TM}}-1$,fused silica capillary column $(30 \mathrm{~m} * 0.25 \mathrm{~mm} * 0.25 \mu \mathrm{m}$ film thickness $)$. The selectivity of the products are defined in mole percentages.

\subsection{Microcalorimetry:}

The microcalorimetry studies was carried out in an International Thermal Instruments block in a home built system and all the catalyst samples where pretreated at $420^{\circ} \mathrm{C}$ under vacuum consistent with the literature[44]. Pure ammonia was used as the adsorbate and ammonia adsorption was carried out at room temperature.

\subsection{Results:}

The surface area measurements for the catalysts are listed in table (1). Specific surface areas were found to range from $4.6 \mathrm{~m}^{2} / \mathrm{g}$ for $\mathrm{H}_{3} \mathrm{PMo}_{12} \mathrm{O}_{40}$ to $13.4 \mathrm{~m}^{2} / \mathrm{g}$ for $\mathrm{NbPMo}_{12} \mathrm{O}_{40} \mathrm{Pyr}$. The addition of either niobium or pyridine caused an increase in surface area with the largest increase for the sample with both niobium and pyridine. 


\begin{tabular}{|l|c|}
\hline Catalyst & Surface Area $\left(\mathrm{m}^{2} / \mathrm{g}\right)$ \\
\hline $\mathrm{H}_{3} \mathrm{PMo}_{12} \mathrm{O}_{40}$ & 4.6 \\
\hline $\mathrm{NbPMo}_{12} \mathrm{O}_{40}$ & 5.9 \\
\hline $\mathrm{PMo}_{12} \mathrm{O}_{40} \mathrm{pyr}$ & 7.6 \\
\hline $\mathrm{NbPMo}_{12} \mathrm{O}_{40} \mathrm{pyr}$ & 13.4 \\
\hline
\end{tabular}

All samples, activated at $420^{\circ} \mathrm{C}$

\section{Table 1: Surface Area Measurements}

Ammonia adsorption microcalorimetry results considered are shown in figure (3-1). Catalytic sites are the stronger sites on the left side in the figure (3-1) and the large number of sites on the right is physisorption sites and will not be further considered. The strong sites at less than $200 \mu \mathrm{mol} / \mathrm{g}$ uptake are more closely shown in figure (3-2). The heat of adsorption for the $\mathrm{H}_{3} \mathrm{PMo}_{12} \mathrm{O}_{40}$ parent catalyst is about $80 \mathrm{~kJ} / \mathrm{mol}$ for initial adsorption and decreases fairly linearly to $0 \mathrm{~kJ} / \mathrm{mol}$ with a total $\mathrm{NH}_{3}$ uptake of approximately $130 \mu \mathrm{mol} / \mathrm{g}$. Incorporation of niobium, pyridine or both to the parent catalyst increases the number of adsorption sites as shown in figure (3-1). Niobium, pyridine or both increases the initial heat of adsorption by about $40 \mathrm{~kJ} / \mathrm{mol}$ to $120 \mathrm{~kJ} / \mathrm{mol}$. From an initial value of $120 \mathrm{~kJ} / \mathrm{mol}$, the pyridine sample heat of adsorption decreases to $\sim 50 \mathrm{~kJ} / \mathrm{mol}$ value for physorption (beyond $200 \mu \mathrm{mol} / \mathrm{g}$ uptake). Similarly, the niobium sample decreased to approximately $\sim 60 \mathrm{~kJ} / \mathrm{mol}$ for physisorption. Finally, both niobium 
and pyridine resulted in a heat of adsorption of $\sim 80 \mathrm{~kJ} / \mathrm{mol}$ for physisorption. After the initial $50 \mu \mathrm{mol} / \mathrm{g}$ uptake, the catalyst with both niobium and pyridine typically had adsorption strength $\sim 10 \mathrm{~kJ} / \mathrm{mol}$ stronger than the other catalysts.

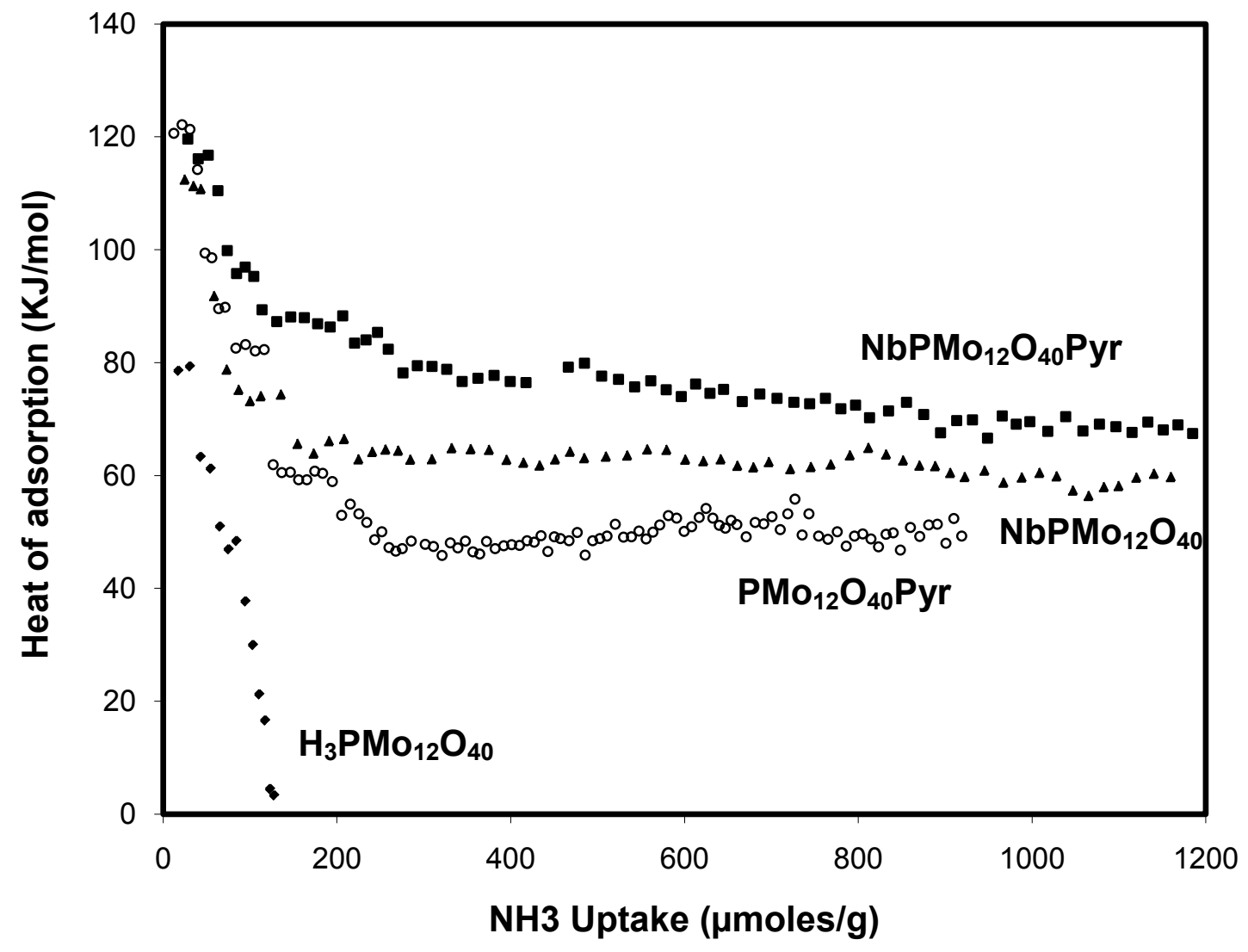

Figure (3-1) - $\mathrm{NH}_{3}$ uptake and heat of adsorption of the catalysts showing the active sites. All the catalysts activated at $420^{\circ} \mathrm{C}$ 


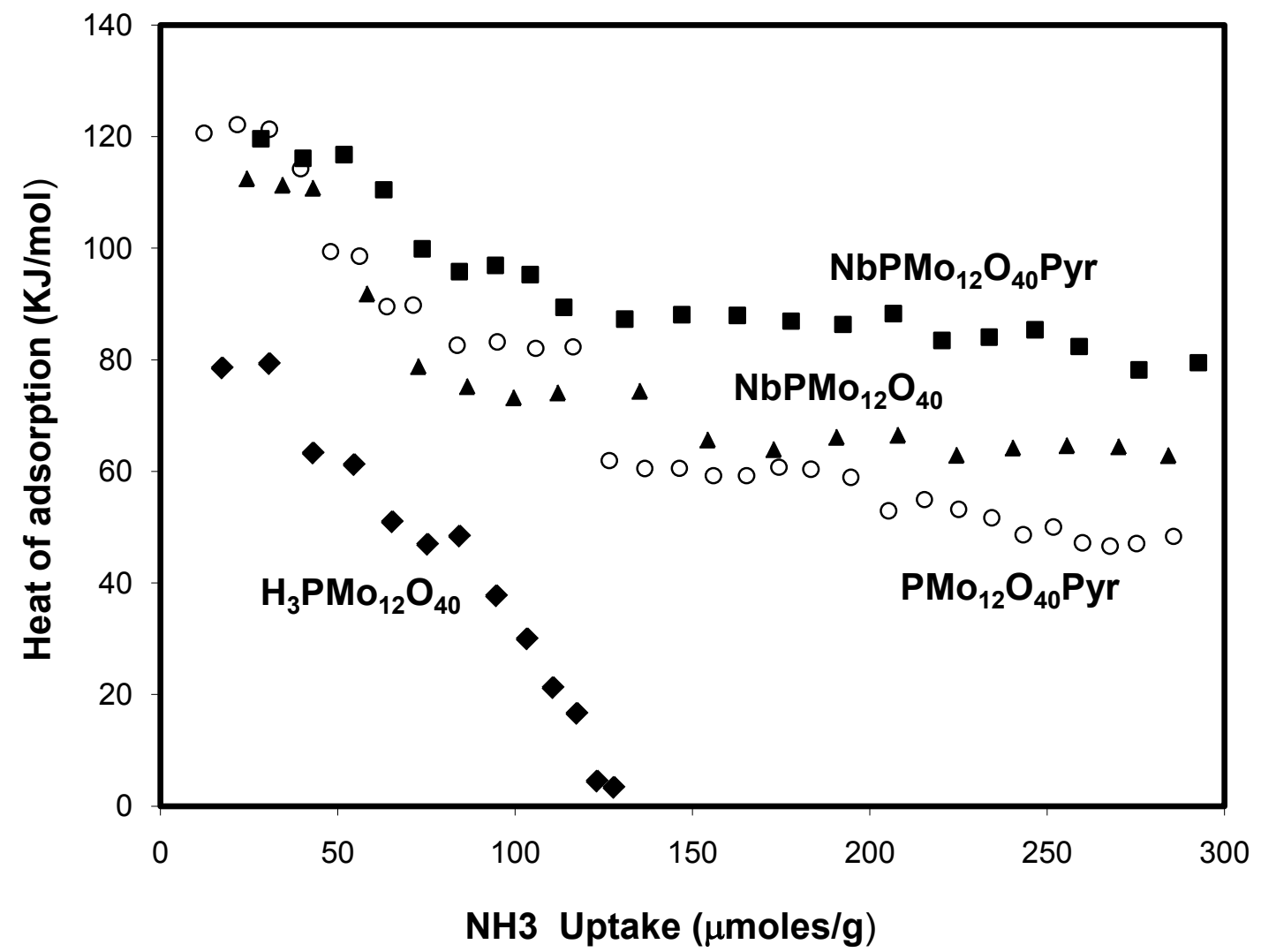

Figure (3-2) - $\mathrm{NH}_{3}$ uptake and heat of adsorption of the catalysts showing the active sites. All the catalysts activated at $420^{\circ} \mathrm{C}$

Conversion of methanol and selectivity as a function of time for $\mathrm{H}_{3} \mathrm{PMo}_{12} \mathrm{O}_{40}$ catalyst are shown in figures (3-3) and (3-4). For $\mathrm{H}_{3} \mathrm{PMo}_{12} \mathrm{O}_{40}$ catalyst, the conversion of methanol increased to about $\sim 20 \%$ within 20 minutes and then decreased. At approximately 50 minutes time on stream, the conversion was $10 \%$ and the selectivity at this point was used for comparison with the other catalysts. The products formed from the reaction are dimethyl-ether (DME) from acidic sites and dimethoxy-methane (DMM) from redox sites. The selectivity of the redox product DMM was as high as $95 \%$ and that of the 
acidic product DME 5\% at 10\% conversion of methanol. Selectivity as a function of time is shown in figure (3-4). Although conversion decreased after an initial incubation period, selectivity was fairly constant over the entire time.

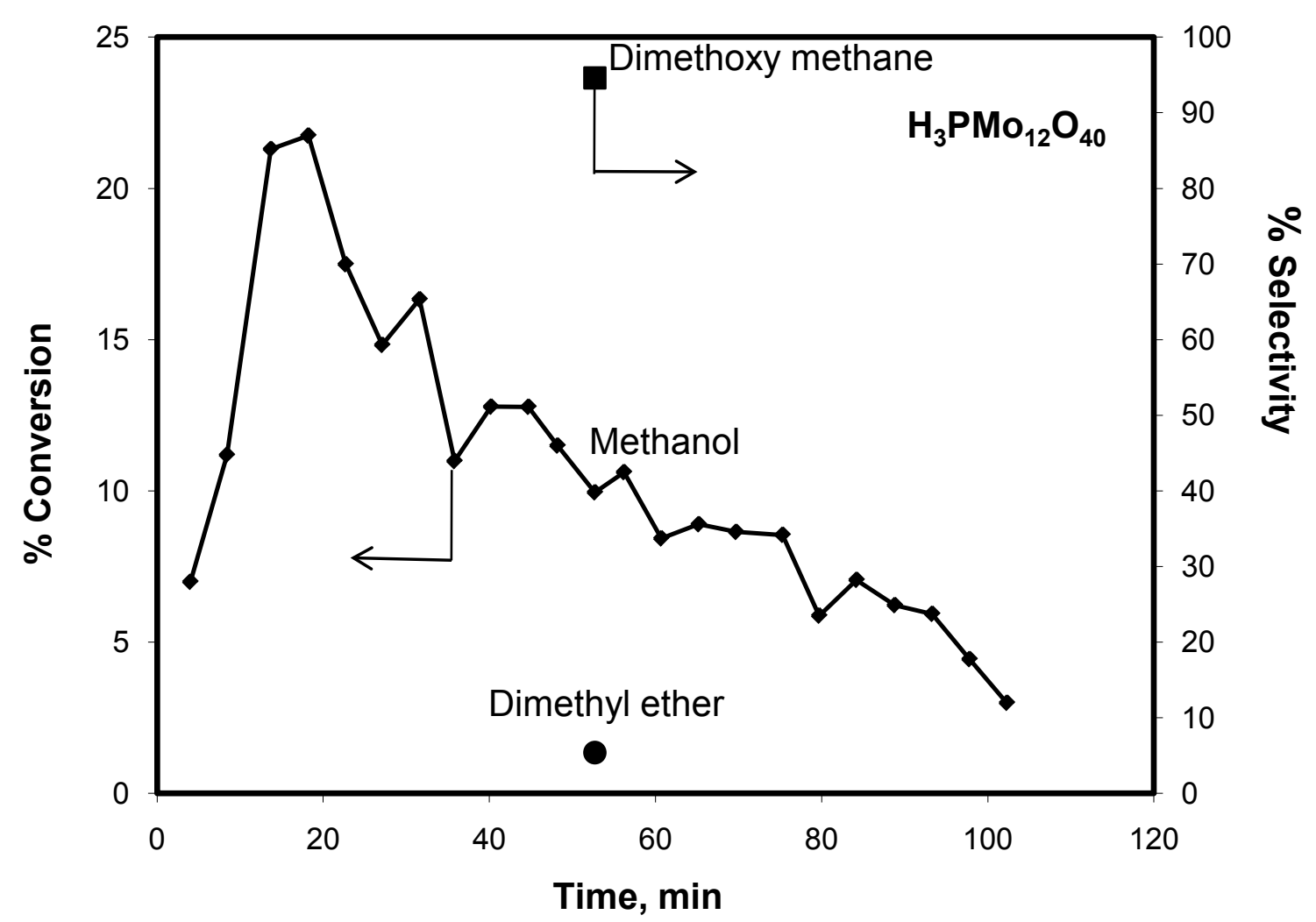

Figure (3-3) - Conversion and selectivity of $\mathrm{H}_{3} \mathrm{PMo}_{12} \mathrm{O}_{40}$ catalyst as a function of time. The reaction was carried out at $260^{\circ} \mathrm{C}$ and with $0.02 \mathrm{~g}$ of catalyst and a total flowrate of 96.2 $(\mathrm{ml} / \mathrm{min})\left(\mathrm{He} / \mathrm{O}_{2} / \mathrm{MeOH}=67.69 / 11.95 / 16.2 \mathrm{ml} / \mathrm{min}\right)$ 


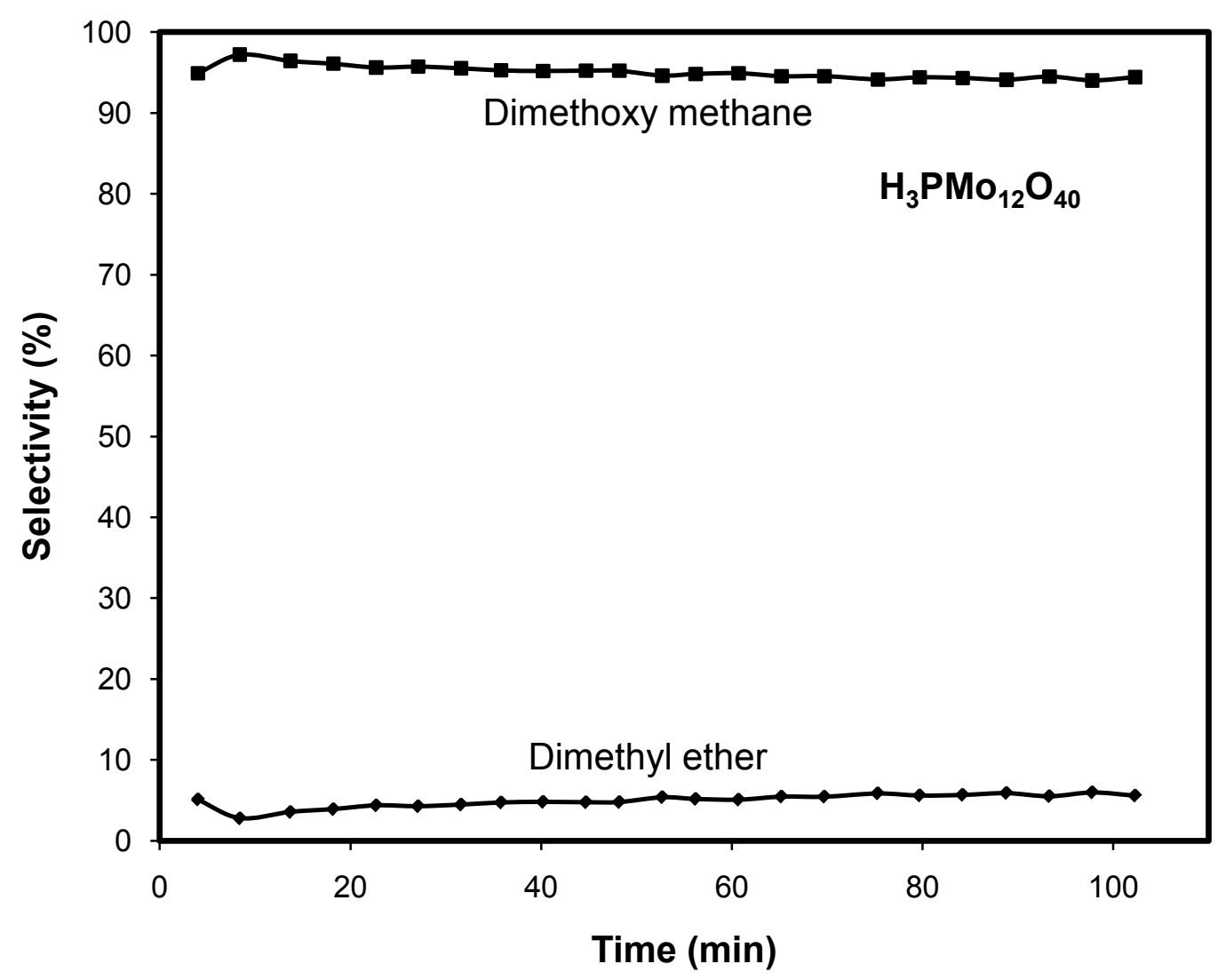

Figure (3-4) - Selectivity of all products as a function of time of $\mathrm{H}_{3} \mathrm{PMo}_{12} \mathrm{O}_{40}$ catalyst. The reaction was carried out at $260^{\circ} \mathrm{C}$ and with $0.02 \mathrm{~g}$ of catalyst and a total flowrate of 96.2 $(\mathrm{ml} / \mathrm{min})\left(\mathrm{He} / \mathrm{O}_{2} / \mathrm{MeOH}=67.69 / 11.95 / 16.2 \mathrm{ml} / \mathrm{min}\right)$

The conversion of methanol and selectivity as a function of time for $\mathrm{NbPMo}_{12} \mathrm{O}_{40}$ catalyst are shown in figure (3-5) and (3-6). Here the conversion of methanol was maintained at a range of about $10-15 \%$ for almost 120 minutes and did not decrease over time like the $\mathrm{H}_{3} \mathrm{PMo}_{12} \mathrm{O}_{40}$ catalyst. The products after reaction are DME (acidic) and DMM (redox). The selectivity of the redox product DMM was slightly lower compared to $\mathrm{H}_{3} \mathrm{PMo}_{12} \mathrm{O}_{40}$ 
catalyst at $93 \%$ with a corresponding slight increase in the selectivity of DME (acidic) product to $7 \%$.

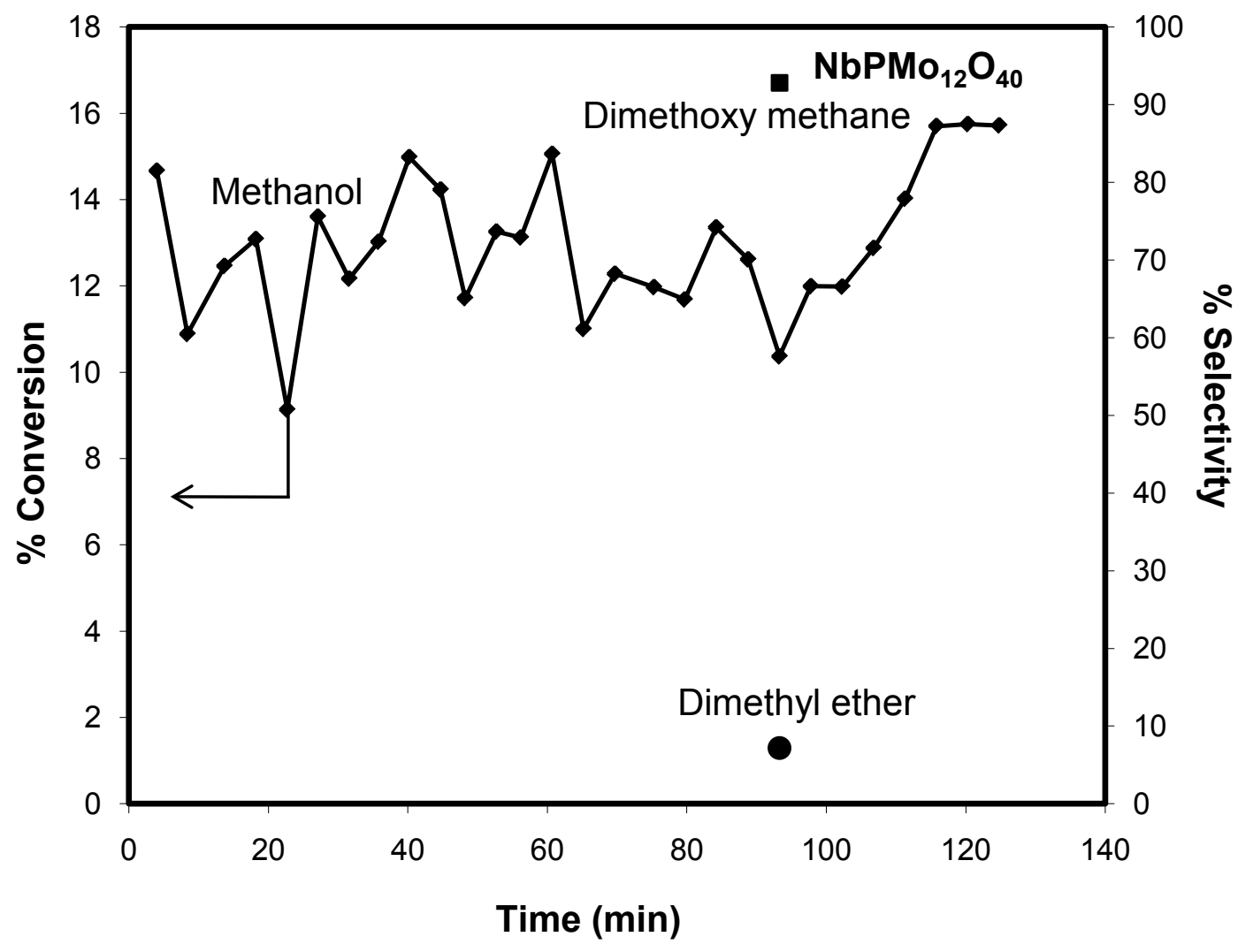

Figure (3-5) - Conversion and selectivity of $\mathrm{NbPMo}_{12} \mathrm{O}_{40}$ catalyst as a function of time. The reaction was carried out at $260^{\circ} \mathrm{C}$ and with $0.04 \mathrm{~g}$ of catalyst and a total flowrate of $108.2(\mathrm{ml} / \mathrm{min})\left(\mathrm{He} / \mathrm{O}_{2} / \mathrm{MeOH}=76.5 / 13.5 / 18.2 \mathrm{ml} / \mathrm{min}\right)$. 


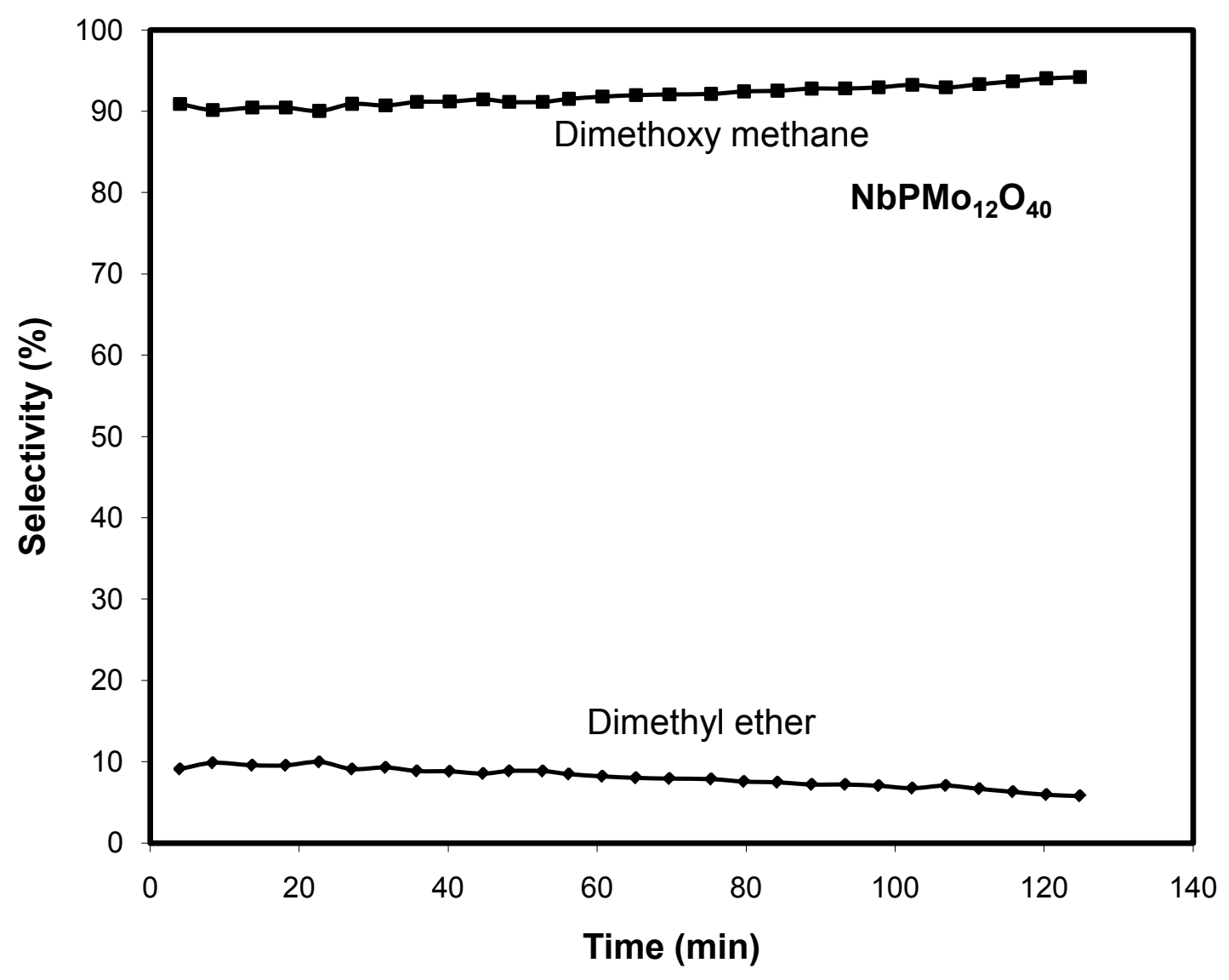

Figure (3-6) - Selectivity of all products as a function of time of $\mathrm{NbPMo}_{12} \mathrm{O}_{40}$ catalyst. The reaction was carried out at $260^{\circ} \mathrm{C}$ and with $0.04 \mathrm{~g}$ of catalyst and a total flowrate of $108.2(\mathrm{ml} / \mathrm{min})\left(\mathrm{He} / \mathrm{O}_{2} / \mathrm{MeOH}=76.5 / 13.5 / 18.2 \mathrm{ml} / \mathrm{min}\right)$.

The conversion of methanol and selectivity as a function of time for $\mathrm{PMo}_{12} \mathrm{O}_{40} \mathrm{pyr}$ catalyst are shown in figure (3-7) and (3-8). The conversion of methanol was maintained at around $10 \%$ for about 75 minutes and then started to decrease with time. The products formed are DME (acidic), DMM (redox) and a very small amount of formaldehyde (redox). At $10 \%$ conversion, the selectivity of the acidic product DME was $62 \%$, the 
selectivity of the redox product DMM was $38 \%$ and a small selectivity of formaldehyde $<1.0 \%$ was observed. With pyridine in the catalyst the selectivity of the acidic product increased and the selectivity of the redox product decreased, in contrast with the parent and niobium exchanged catalyst. In figure (3-8), the selectivity of all products as a function of time is shown for $\mathrm{PMo}_{12} \mathrm{O}_{40}$ pyr catalyst. Here it is seen that the selectivity of DME (acidic) is higher initially at around $75 \%$ and then decreases to about $45 \%$ over 150 minutes. The selectivity of DMM (redox) was initially low at about $23 \%$ and then increased to around $60 \%$ over 150 minutes. After about 80 minutes the selectivity of DMM (redox) overtakes the selectivity of DME (acidic). Following an initial transient, the selectivity of DME decreased and the selectivity of DMM increased with time on stream. These selectivity changes occur simultaneously with the catalyst deactivation. In contrast with the other catalysts, only selectivity for the pyridine sample showed the most variability as a function of time on stream. 


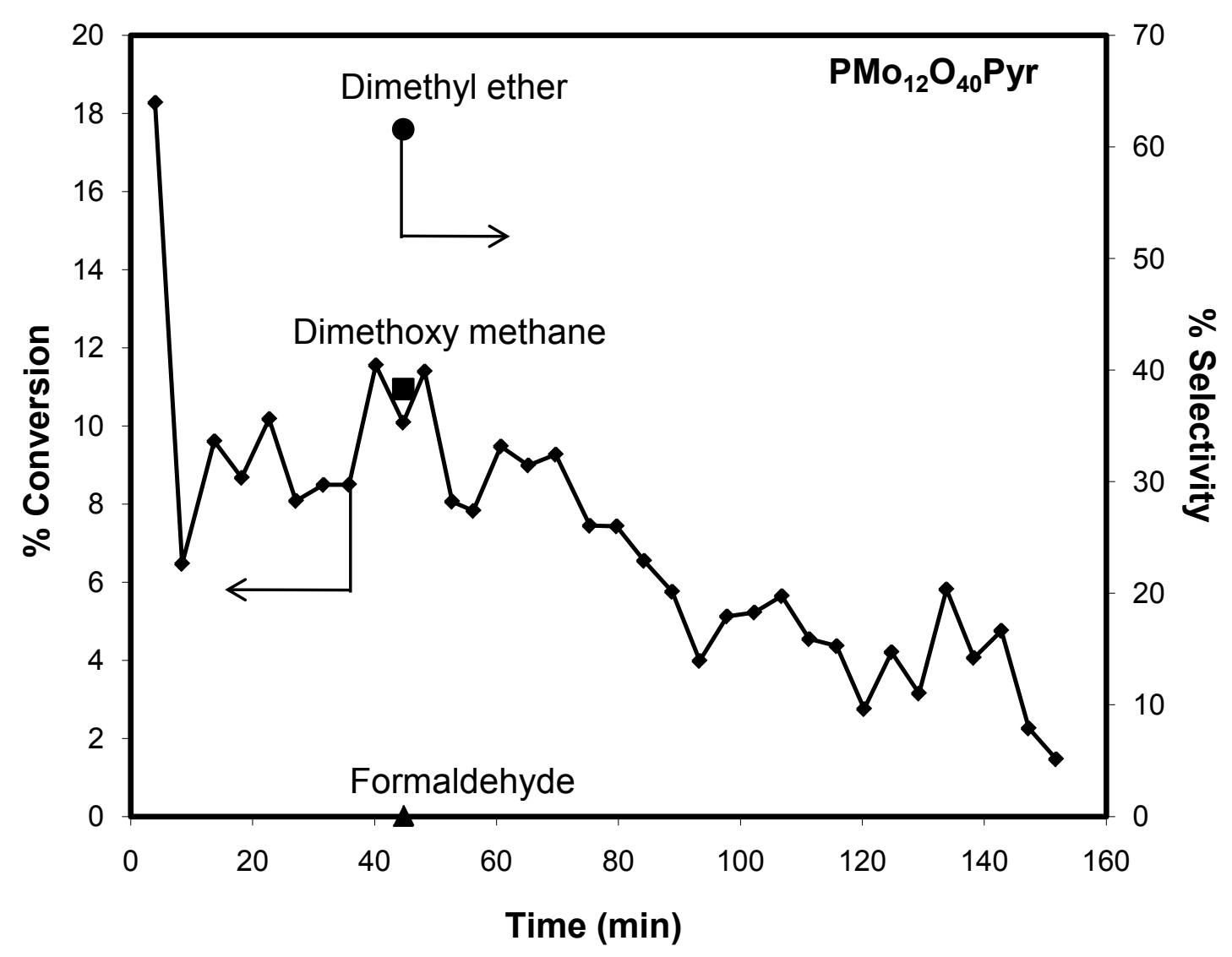

Figure (3-7) - Conversion and selectivity of $\mathrm{PMo}_{12} \mathrm{O}_{40} \mathrm{Pyr}$ catalyst as a function of time. The reaction was carried out at $260^{\circ} \mathrm{C}$ and with $0.04 \mathrm{~g}$ of catalyst and a total flowrate of $108.2(\mathrm{ml} / \mathrm{min})\left(\mathrm{He} / \mathrm{O}_{2} / \mathrm{MeOH}=76.5 / 13.5 / 18.2 \mathrm{ml} / \mathrm{min}\right)$. 


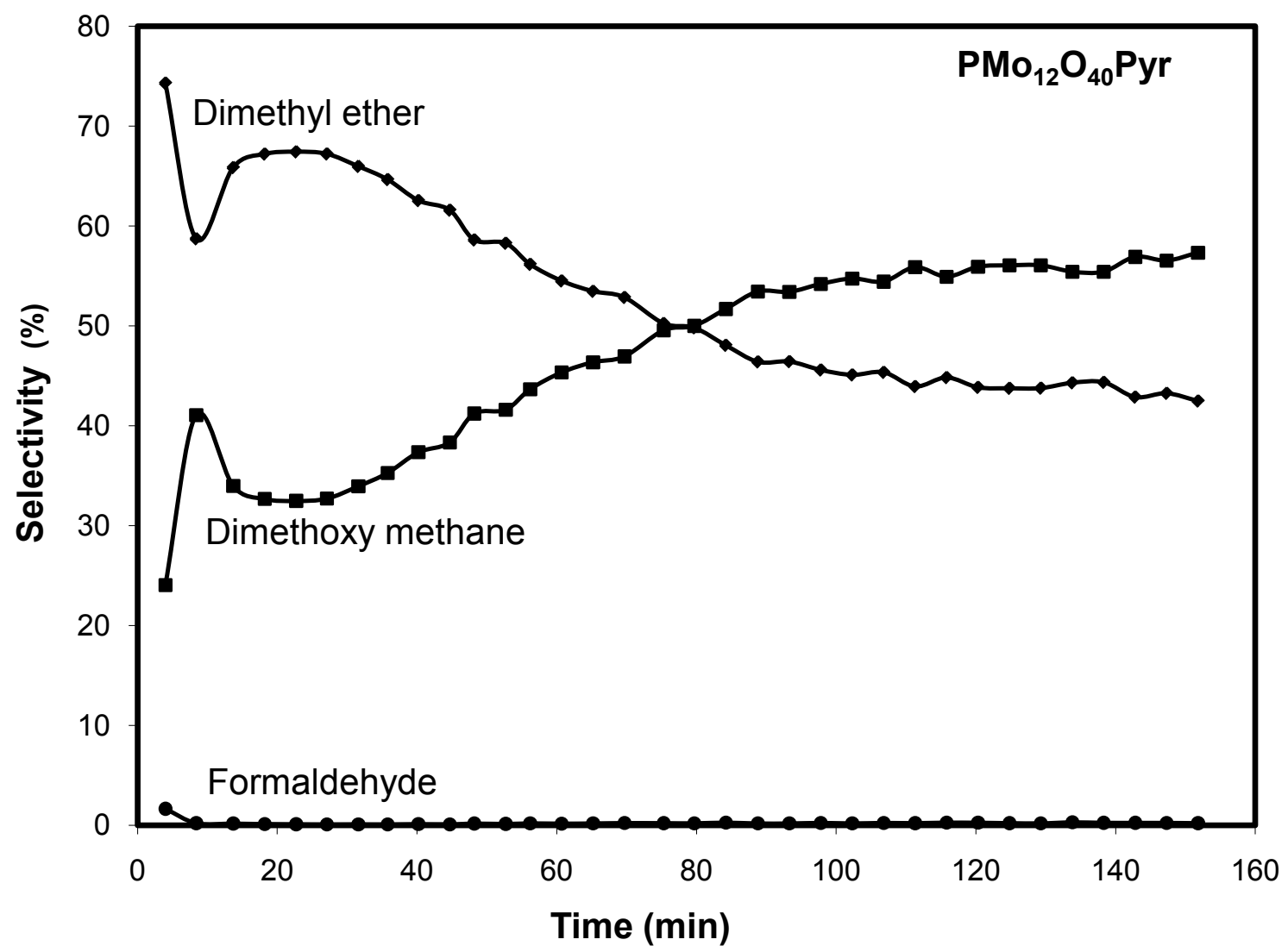

Figure (3-8) - Selectivity of all products as a function of time of $\mathrm{PMo}_{12} \mathrm{O}_{40} \mathrm{Pyr}$ catalyst. The reaction was carried out at $260^{\circ} \mathrm{C}$ and with $0.04 \mathrm{~g}$ of catalyst and a total flowrate of $108.2(\mathrm{ml} / \mathrm{min})\left(\mathrm{He} / \mathrm{O}_{2} / \mathrm{MeOH}=76.5 / 13.5 / 18.2 \mathrm{ml} / \mathrm{min}\right)$.

The conversion of methanol and selectivity as a function of time for $\mathrm{NbPMo}_{12} \mathrm{O}_{40}$ pyr catalyst are shown in figure (3-9) and (3-10). The conversion of methanol was around $10 \%$ between $20-58$ minutes and increased gradually with time. The products formed are DME (acidic), DMM (redox) and very small amount formaldehyde (redox). The 
selectivity of the acidic product DME was very high at $95 \%$, the selectivity of the redox product DMM was $5 \%$ and a small selectivity to formaldehyde of $<1 \%$ was seen.

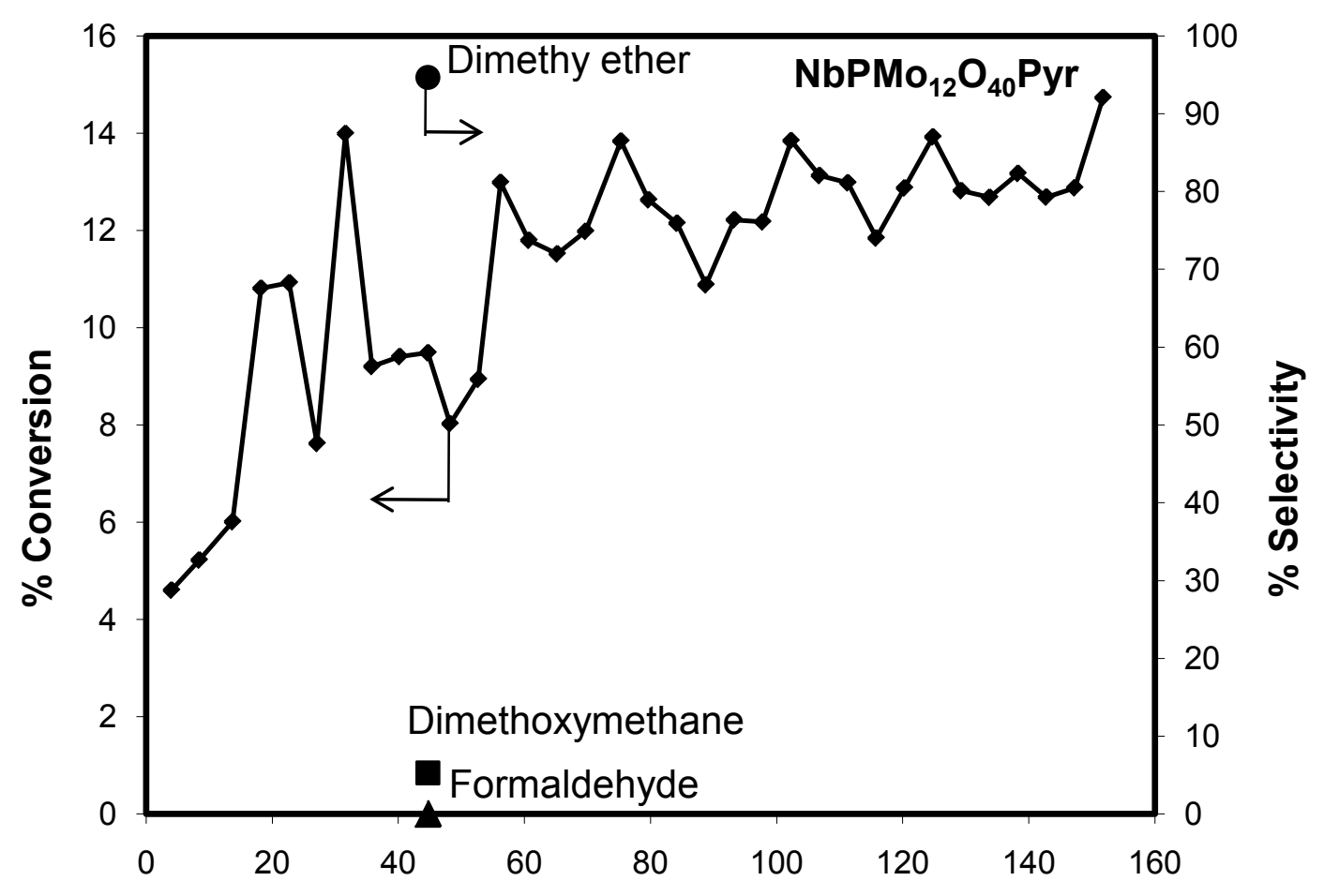

Time, $\min$

Figure (3-9) - Conversion and selectivity of $\mathrm{NbPMo}_{12} \mathrm{O}_{40} \mathrm{Pyr}$ catalyst as a function of time. The reaction was carried out at $260^{\circ} \mathrm{C}$ and with $0.01 \mathrm{~g}$ of catalyst and a total flow-rate of $157.3(\mathrm{ml} / \mathrm{min})\left(\mathrm{He} / \mathrm{O}_{2} / \mathrm{MeOH}=115.2 / 20.44 / 27.34 \mathrm{ml} / \mathrm{min}\right)$. 


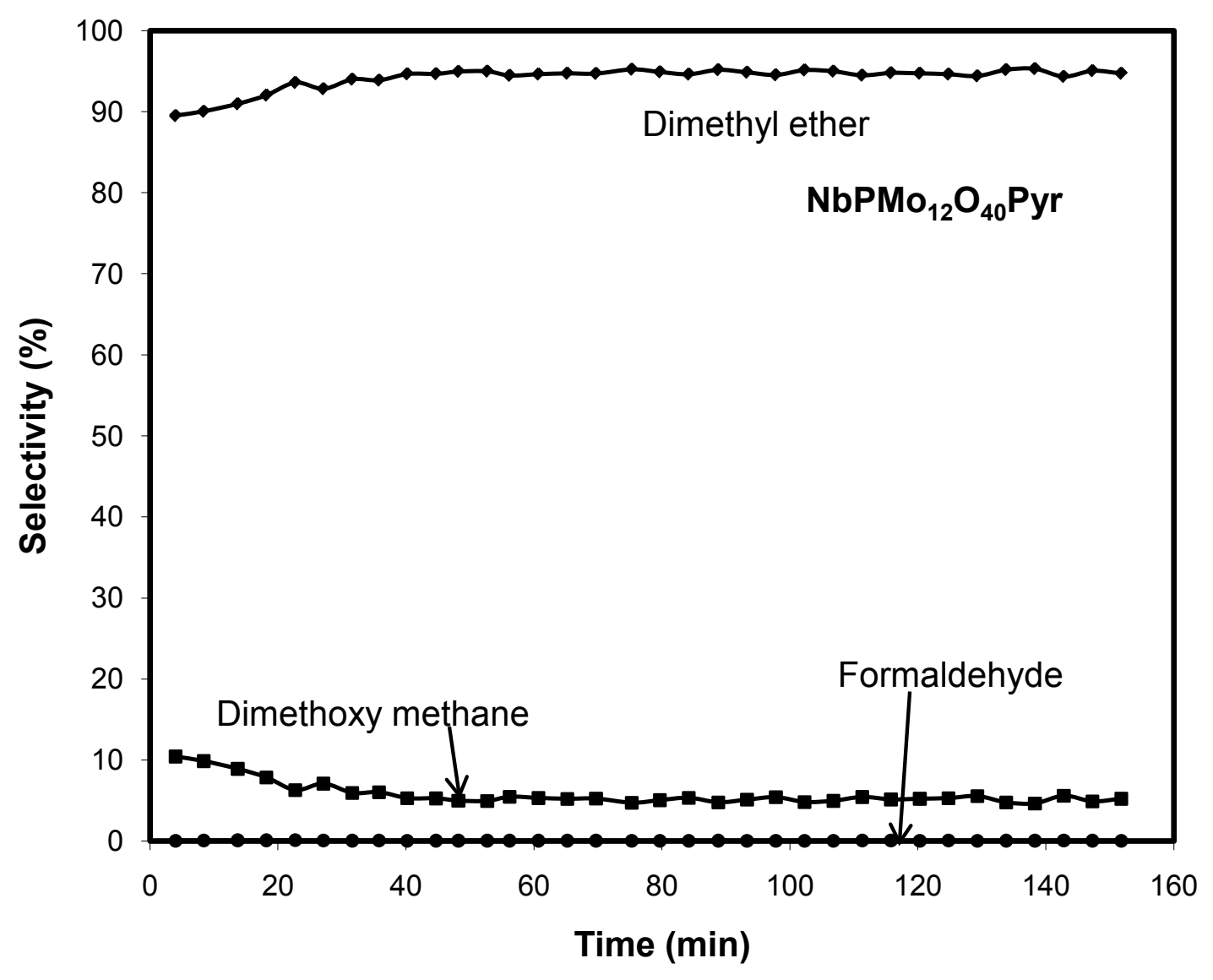

Figure (3-10) - Selectivity of all products as a function of time of $\mathrm{NbPMo}_{12} \mathrm{O}_{40} \mathrm{Pyr}$ catalyst. The reaction was carried out at $260^{\circ} \mathrm{C}$ and with $0.01 \mathrm{~g}$ of catalyst and a total flow-rate of $157.3(\mathrm{ml} / \mathrm{min})\left(\mathrm{He} / \mathrm{O}_{2} / \mathrm{MeOH}=115.2 / 20.44 / 27.34\right.$ $\mathrm{ml} / \mathrm{min})$.

The selectivity of all products as a function of time is shown in figure (3-10) for $\mathrm{NbPMo}_{12} \mathrm{O}_{40}$ pyr catalyst. When niobium and pyridine was combined with the parent catalyst the selectivity of DME (acidic) product was high, above 90\%, and did not decrease as in the case of $\mathrm{PMo}_{12} \mathrm{O}_{40}$ pyr catalyst figure (3-8). The selectivity of DMM (redox) decreased slightly from about $10 \%$ and remained constant around 6\%. Small 
traces of formaldehyde (redox) were also noticed. In contrast with the pyridine only sample, all selectivities were fairly constant as a function of time.

In table (2) the rate of reactivity of the products for each catalyst is reported at $10 \%$ conversion. When niobium was incorporated, the rate of formation both acidic and redox products decreased when compared to the parent catalyst.. Addition of pyridine to the parent catalyst decreased the rate of DMM (redox) production by a factor of 6 and increased the production rate of the acidic product by a factor of 4 compared to the parent catalyst. The highest reaction rate to the acidic product occurs when both niobium and pyridine was incorporated to $\mathrm{H}_{3} \mathrm{PMo}_{12} \mathrm{O}_{40}$ catalyst. This rate was 7.5 times the rate of the next highest catalyst.

\begin{tabular}{|c|c|c|c|}
\hline Catalyst & $\begin{array}{c}\text { DME(Acidic) } \\
(\mathrm{mmol} / \mathrm{min} \\
\left.\mathrm{m}^{2}\right)\end{array}$ & $\begin{array}{c}\mathrm{DMM}(\text { Redox }) \\
\left(\mathrm{mmol} / \mathrm{min} \mathrm{m}^{2}\right)\end{array}$ & $\begin{array}{c}\text { Formaldehyde(Redox) } \\
\left(\mathrm{mmol} / \mathrm{min} \mathrm{m}^{2}\right)\end{array}$ \\
\hline $\mathrm{H}_{3} \mathrm{PMo}_{12} \mathrm{O}_{40}$ & $1.5 \times 10^{-7}$ & $2.7 \times 10^{-6}$ & - \\
\hline $\mathrm{NbPMo}_{12} \mathrm{O}_{40}$ & $1.0 \times 10^{-7}$ & $1.3 \times 10^{-6}$ & - \\
\hline $\mathrm{PMo}_{12} \mathrm{O}_{40} \mathrm{pyr}$ & $6.9 \times 10^{-7}$ & $4.2 \times 10^{-7}$ & $9.7 \times 10^{-10}$ \\
\hline $\mathrm{NbPMo}_{12} \mathrm{O}_{40} \mathrm{pyr}$ & $5.1 \times 10^{-6}$ & $2.8 \times 10^{-7}$ & $3.2 \times 10^{-9}$ \\
\hline
\end{tabular}

Table 2: Reactivity of the catalyst $\left(\mathrm{mmol} / \mathrm{min}^{2}\right)$ at $260^{\circ} \mathrm{C}$, around $10 \%$ conversion.

Catalyst reactivity of the products formed using methanol as substrate 
In table (3) the selectivity of the products at $10 \%$ conversion is reported. The parent catalyst had selectivity $>90 \%$ for DMM (redox). With the addition of niobium to $\mathrm{H}_{3} \mathrm{PMo}_{12} \mathrm{O}_{40}$ catalyst a slight increase of about $\sim 2 \%$ was noticed in the selectivity of the DME (acidic). With the pyridine exchanged catalyst, the selectivity of DME increased to about $\sim 62 \%$, selectivity of DMM (redox) decreased to about $\sim 38 \%$ and for formaldehyde (redox) it was $>1 \%$ at $10 \%$ conversion. The niobium and pyridine exchanged catalyst had selectivity to DME (acidic) at $\sim 95 \%$, almost completely reversing the high selectivity of the parent catalyst from DMM (redox) to DME (acidic). The selectivity of formaldehyde was $>1 \%$.

\begin{tabular}{|c|c|c|c|}
\hline Catalyst & DME(Acidic) & DMM(Redox) & Formaldehyde(Redox) \\
\hline $\mathrm{H}_{3} \mathrm{PMo}_{12} \mathrm{O}_{40}$ & 5.4 & 94.6 & - \\
\hline $\mathrm{NbPMo}_{12} \mathrm{O}_{40}$ & 7.2 & 92.8 & 0.087 \\
\hline $\mathrm{PMo}_{12} \mathrm{O}_{40} \mathrm{pyr}$ & 61.5 & 38.3 & 0.059 \\
\hline $\mathrm{NbPMo}_{12} \mathrm{O}_{40} \mathrm{pyr}$ & 94.6 & 5.3 & - \\
\hline
\end{tabular}

Table 3: Catalyst Selectivity (\%) at $260^{\circ} \mathrm{C}$, around $10 \%$ conversion.

\section{Catalyst selectivity of the products formed using methanol as substrate}




\subsection{Discussion:}

The literature reactivity results for production of maleic acid from n-butane show that the most active and selective catalyst is the niobium and pyridine exchanged phosphomolybdic acid $\left(\mathrm{NbPMo}_{12} \mathrm{O}_{40}\right.$ pyr)[1]. However, by closely examining the activity and selectivity effect for each component, a better understanding of the contribution of each component to the catalyst can be elucidated. The parent $\mathrm{H}_{3} \mathrm{PMo}_{12} \mathrm{O}_{40}$ catalyst showed the lowest activity with selectivity mainly to combustion products[1]. The addition of niobium to the parent catalyst resulted in increased activity with the selectivity now mainly to the desired maleic acid product[1]. The addition of pyridine to the parent catalyst also resulted in increased activity and selectivity to the desired product. Pyridine increased the activity more than niobium, but both had similar selectivities. Finally, the combination of both niobium and pyridine resulted in the highest activity and selectivity.

Auroux and Gervasini have reported the study of acidity and basicity on metal oxides surfaces[9] and have used microcalorimetry in order to determine the number and character of basic and acidic surface sites. Adsorption microcalorimetry has also been used to study the acidity of heteropolycomponents using ammonia[10, 15, 21, 22]. Interactions with acid sites in solids are often studied with ammonia because it is one of the simplest molecules and is also the most studied basic probe molecule[15]. Strong acids bind more strongly with ammonia than weaker acids. 
When pyridine was added to the parent catalyst, the initial heat of adsorption was $\sim 10 \mathrm{~kJ} / \mathrm{mol}$ higher than for niobium addition to the parent catalyst. At increased uptake, the pyridine sample heat of adsorption was equal to or slightly greater than the niobium sample until the ammonia dosing exceeded $120 \mu \mathrm{mol} / \mathrm{g}$. When both niobium and pyridine were incorporated in the parent sample, the initial heat of adsorption was equivalent to the pyridine only sample. However, as ammonia dosing increased, the niobium and pyridine sample continued to show stronger sites than either of the samples with only niobium or pyridine. Thus, the combination of both niobium and pyridine resulted in a higher number of stronger sites. These sites were $10-20 \mathrm{~kJ} / \mathrm{mol}$ stronger after the initial adsorption. While the most active catalyst for selective oxidation of n-butane $\left(\mathrm{NbPMo}_{12} \mathrm{O}_{40} \mathrm{pyr}\right)$ did have a large number of stronger acid sites, there are no significant differences between the catalysts, which might account for the dramatic increase in activity reported in the literature[1].

The ammonia adsorption result for $\mathrm{H}_{3} \mathrm{PMo}_{12} \mathrm{O}_{40}$ obtained by Jozefowicz et al demonstrated an initial heat of $150 \mathrm{~kJ} / \mathrm{mol}$ when treated at $323 \mathrm{~K}$. Bardin et al showed that the sample pretreated at $473 \mathrm{~K}$ had a higher heat of adsorption $\sim 120 \mathrm{~kJ} / \mathrm{mol}$ than when treated at $573 \mathrm{~K}$, which was $\sim 100 \mathrm{~kJ} / \mathrm{mol}[10]$. The decreasing heat of adsorption as pretreatment temperature increased likely results because the structure started to decompose as the pretreatment temperature increased [10]. The site density also decreased from about $1050 \mu \mathrm{mol} / \mathrm{g}$ to as low as $200 \mu \mathrm{mol} / \mathrm{g}$ as the pretreatment temperature increased from $473 \mathrm{~K}$ to $573 \mathrm{~K}$ [10]. The results in this paper in figure (3-1) and (3-2) shows that the parent catalyst $\mathrm{H}_{3} \mathrm{PMO}_{12} \mathrm{O}_{40}$ which was pretreated at a higher 
temperature of $698 \mathrm{~K}$ had a lower heat of adsorption of about $\sim 80 \mathrm{~kJ} / \mathrm{mol}$. The total uptake also decreased to $130 \mu$ moles/g. This loss of adsorption strength and sites is consistent with the decomposition of the keggin structure as pretreatment temperature increases as shown by phosphorous NMR[45]. However, when niobium, pyridine or both was incorporated into the parent $\mathrm{H}_{3} \mathrm{PMO}_{12} \mathrm{O}_{40}$ catalyst that was pretreated at $698 \mathrm{~K}$, the initial heat of adsorption is the same as with that of the parent catalyst pretreated at $473 \mathrm{~K}$ shown in the work of Bardin et al [10]. The number of strong adsorption sites is also increased upon incorporation of niobium, pyridine or both.

Previously, Xue et al have shown that the ammonia adsorption studies on $\mathrm{MoO}_{3}$ at $423 \mathrm{~K}$ produced initial heat lower than $20 \mathrm{~kJ} / \mathrm{mol}$ [31]. Thus, the active sites in these catalysts are clearly not just molybdenum oxide. Jin et al have reported that the initial heat of adsorption to be about $\sim 90 \mathrm{~kJ} / \mathrm{mol}$ for $\mathrm{Nb}_{2} \mathrm{O}_{5}$ ammonia adsorption studies[28]. Sun et al have showed at $423 \mathrm{~K}$ the initial heat of adsorption for $\mathrm{Nb}_{2} \mathrm{O}_{5}$ was $\sim 150 \mathrm{~kJ} / \mathrm{mol}$ with ammonia uptake of $280 \mu \mathrm{mol} / \mathrm{g}[29]$. But, Petre et al have shown the initial heat of adsorption to be $\sim 125 \mathrm{~kJ} / \mathrm{mol}$ at $353 \mathrm{~K}$ and $423 \mathrm{~K}$ with ammonia uptake of $190 \mu \mathrm{mol} / \mathrm{g}$ and $250 \mu \mathrm{mol} / \mathrm{g}$ respectively for $\mathrm{Nb}_{2} \mathrm{O}_{5}$. While these initial heats for ammonia adsorption on $\mathrm{Nb}_{2} \mathrm{O}_{5}$ are consistent the values for on niobium containing catalyst, we also observe similar heats for non-niobium containing catalysts (i.e., pyridine only).

During oxidation of methanol, the surface methoxy groups are the intermediate species in the production of partially oxygenated reaction products such as formaldehyde, dimethyl ether, dimethoxymethane, methylformate etc.[33, 46]. The products formed depend on 
the nature of the active sites: acidic, basic or redox. The products obtained from the reaction of our catalysts are dimethyl ether (acidic), dimethoxymethane (redox) and formaldehyde (redox). From Tatibouët [33], the methanol reaction on oxide surfaces is very sensitive to the nature of surface active sites which can lead to the formation of various products by methanol oxidation. Methanol oxidation reactions can be categorized into oxidation reactions that need oxygen and dehydration reactions that need no oxygen. The formation of all products except for DME (acidic) needs at least one oxidation step. Selectivity of DME (acidic) is attributed to the dehydration capability of the catalyst which in turn is related to its own acidic character [8].

Methanol oxidation reaction result from figure (3-3) for $\mathrm{H}_{3} \mathrm{PMo}_{12} \mathrm{O}_{40}$ catalyst shows conversion of methanol and selectivity at $10 \%$ conversion as a function of time. After the initiation period, the catalyst activity decreases over time and has high selectivity for the redox product DMM $\sim 95 \%$ and about $\sim 5 \%$ for the acid product DME. The selectivity of the products as a function of time from figure (3-4) shows that there is no change in the selectivity even though the catalyst deactivates as shown in figure (3-3). Although no direct literature comparisons are available, this catalyst is known to decompose at pretreatment conditions in excess of $440^{\circ} \mathrm{C}$ to $\mathrm{MoO}_{3}[45]$. Wachs et al reported high selectivity of redox products for methanol oxidation studies on $\mathrm{MoO}_{3}[3,8]$. The presence of similar selectivity from $\mathrm{H}_{3} \mathrm{PMo}_{12} \mathrm{O}_{40}$ and $\mathrm{MoO}_{3}$ suggests the similarity of active sites. 
The addition of niobium to the parent catalyst stabilizes the catalyst as shown in figure (3-5). The conversion is almost stable and the catalyst does not deactivate as that of $\mathrm{H}_{3} \mathrm{PMo}_{12} \mathrm{O}_{40}$ in figure (3-5). With the addition of niobium, the selectivity of the acid product increased slightly to about $\sim 7 \%$ and the selectivity of DMM (redox) decreased slightly to about $\sim 93 \%$. Similar to $\mathrm{H}_{3} \mathrm{PMo}_{12} \mathrm{O}_{40}$, the selectivity for the $\mathrm{NbPMo}_{12} \mathrm{O}_{40}$ catalyst remained constant as a function of time on stream. In contrast with $\mathrm{MoO}_{3}$, methanol oxidation studies carried out by Wachs et al on $\mathrm{Nb}_{2} \mathrm{O}_{5}$ demonstrated a high selectivity for the acidic product $[8,47]$. Thus, the slight increase in selectivity of the acid product when niobium was added to the parent catalyst is consistent with the addition of some active niobium sites.

In figure (3-7) when pyridine is added to the parent catalyst $\mathrm{H}_{3} \mathrm{PMo}_{12} \mathrm{O}_{40}$, it is seen that after 60 minutes the catalyst starts to deactivate. However, the important observation was the increase in the selectivity of the acid product which was as high as $\sim 62 \%$ compared with that of $\mathrm{NbPMo}_{12} \mathrm{O}_{40}$ which was less than $10 \%$ for acidic product. The selectivity of the redox product dropped to $\sim 38 \%$ (at $10 \%$ conversion) from about $\sim 92 \%$ with the addition of pyridine instead of niobium to the parent catalyst. Small traces of formaldehyde were also observed $(<1 \%)$. Figure (3-8) shows the selectivity of the products as a function of time and the important finding was the selectivity of DME (acidic) was high at about $\sim 75 \%$ and later decreased to about $45 \%$ over time and the selectivity of the redox product increased gradually from about $\sim 23 \%$ to about $\sim 60 \%$. The switch in product selectivity occurred in parallel with the loss of activity. The selectivity of the redox product was more than that of acid product after about 80 
minutes. This result is consistent with the ammonia adsorption results in figure (3-1) where it is seen that the catalyst with pyridine has the highest initial heat of adsorption and is thus the strongest acid. Pyridine increases the strength of acid sites in the catalyst but does not stabilize the catalyst like niobium (figure (3-5) and (6)).

When both niobium and pyridine are incorporated into the parent catalyst $\mathrm{H}_{3} \mathrm{PMo}_{12} \mathrm{O}_{40}$, the methanol oxidation result for the conversion and selectivity of the products as a function of time are shown in figure (3-9) and (3-10). The conversion of the catalyst remains constant over time (figure (3-9)) which is similar to the $\mathrm{NbPMo}_{12} \mathrm{O}_{40}$ catalyst (figure (3-5)). The selectivity of the acid product, dimethyl ether, is very high at $\sim 95 \%$ and that of the redox product, dimethoxy methane, was about $~ 5 \%$ at $10 \%$ conversion of methanol. This selectivity shows similarity with $\mathrm{H}_{3} \mathrm{PMo}_{12} \mathrm{O}_{40}$ pyr catalyst where the selectivity of DME (acidic) was high initially.

From the figure (3-10) it can be observed that after a very small initial increase, the selectivity of the acid product remained constant. A corresponding small initial decrease was observed in the selectivity of the redox product and it then remained constant. These results agree fairly well with that of the ammonia adsorption microcalorimetry study in figure (3-1) and (3-2), where the $\mathrm{NbPMo}_{12} \mathrm{O}_{40}$ pyr catalyst has consistently stronger acid sites than the other catalysts. The presence of niobium along with pyridine is necessary to obtain the maximum activation of the catalyst. Studies done on molybdenum-based pyridine exchanged heteroployanion catalysts by Holles et al showed that the presence of 
niobium increased the activity and productivity significantly for n-butane oxidation to maleic acid[4, 14, 15].

In this study, the rate of acid, base and redox sites at $260^{\circ} \mathrm{C}$ for conversion of methanol around $10 \%$ shows that the addition of pyridine and niobium has important effects on the parent catalyst. We did not detect the presence of any base sites in the product stream; either they were non-existent or too small to measure. Wachs et al observed redox and acidic products for methanol oxidation of $\mathrm{MoO}_{3}$ at $300^{\circ} \mathrm{C}$ and the ratio was $6: 1$ [8]. Our results also show redox and acidic products for $\mathrm{H}_{3} \mathrm{PMo}_{12} \mathrm{O}_{40}$ catalyst and the selectivity of redox products was high. The ratio of redox to acidic product selectivity at $10 \%$ conversion at $260^{\circ} \mathrm{C}$ was 19: 1 for the parent catalyst $\mathrm{H}_{3} \mathrm{PMo}_{12} \mathrm{O}_{40}$. Wachs et al reported only acidic and no redox and base product for $\mathrm{Nb}_{2} \mathrm{O}_{5}$ during methanol oxidation at $300^{\circ} \mathrm{C}$ [8]. While our results show both redox and acidic products for the catalyst with niobium, it should be noted that $\mathrm{NbPMo}_{12} \mathrm{O}_{40}$ catalyst is still mostly Mo with a small amount of niobium. As expected from the literature, the presence of niobium did slightly increase the selectivity of the catalyst to the acidic product.

From Wachs et al work, niobium oxide results only in the acidic product [8]. The addition of niobium decreased the ratio of redox and acidic product selectivity to $13: 1$, clearly showing slightly higher selectivity of the acidic product. The slight increase in selectivity for the $\mathrm{NbPMo}_{12} \mathrm{O}_{40}$ catalyst agrees with the results shown by Wachs et al, where only acidic product was found for $\mathrm{Nb}_{2} \mathrm{O}_{5}$. With the pyridine exchanged catalyst the ratio of redox to acidic product was 1:1.6 at 10\% conversion and inverted compared to 
the parent and niobium exchanged catalyst. This clearly shows that pyridine has a major impact on the acidic product selectivity. From the work of Wachs, no previous oxide gave more acid than redox products[8]. Finally, when both niobium and pyridine was incorporated into the parent catalyst, the ratio of the selectivity of the redox and acidic product further decreased to $1: 19$. This ratio is the opposite of the parent catalyst and higher than the pyridine only catalyst.

Wachs et al has reported three oxides that favor redox product over acidic product: $\mathrm{V}_{2} \mathrm{O}_{5}$, $\mathrm{MoO}_{3}$ and $\mathrm{Fe}_{2} \mathrm{O}_{3}[8]$. The oxides that only favor acidic product (no redox/base) reported by them are $\mathrm{Nb}_{2} \mathrm{O}_{5}, \mathrm{P} 2 \mathrm{O} 5, \mathrm{Ga}_{2} \mathrm{O}_{3}, \mathrm{WO}_{3}, \mathrm{Ta}_{2} \mathrm{O}_{5}$ and $\mathrm{Al}_{2} \mathrm{O}_{3}[8]$. But, none of the oxides reported have the same ratio of redox to acidic product that has been observed in our study for the niobium and pyridine exchanged catalyst. Only two oxides $\mathrm{TiO}_{2}$ and $\mathrm{SiO}_{2}$ have presence of acidic and base product in them[8].

From these results it can be observed that niobium, when added to the parent catalyst, stabilizes the sites and keeps the catalyst active. The pyridine and niobium exchanged catalyst has the most activity and selectivity for acid sites. These results are on similar grounds as that of the results found in the n-butane reactivity studies carried out by Holles et al[1].

From the results of ammonia adsorption and methanol oxidation of the heteroployacid catalysts in our study, it can be noted that the pyridine is main driving factor that increases the strength of active sites. The rate of the reaction for the acidic product is 
higher than that of the redox for catalyst $\mathrm{PMo}_{12} \mathrm{O}_{40}$ pyr and the catalyst $\mathrm{NbPMo}_{12} \mathrm{O}_{40} \mathrm{pyr}$ (Table 2 , at $10 \%$ conversion). This is well reflected with their selectivity in this work (Table 3). In the results of the paper by Holles el al it was shown that niobium and pyridine-exchanged salts of molybophosphoric acid had more activity and selectivity for the selective oxidation of butane[1]. Pyridine increases the surface area of the catalyst so does niobium. But with niobium though the acid sites are increased, it is the redox sites that are very active. Pyridine being more acidic increases the acid sites on the catalyst surface and has been shown in the results of ammonia adsorption (figure (3-1) and (3-2)).

\subsection{Conclusion:}

Microcalorimetry and methanol oxidation studies on polyoxometalate catalysts have been performed. The addition of either niobium or pyridine to the parent $\mathrm{H}_{3} \mathrm{PMo}_{12} \mathrm{O}_{40}$ catalyst results in increased site strength but both have similar heats of adsorption. When both niobium and pyridine are present in the catalyst it does not result in higher ammonia heat of adsorption. However, more strong sites are present when the catalyst is exchanged with both niobium and pyridine.

During methanol oxidation, the parent catalyst $\mathrm{H}_{3} \mathrm{PMo}_{12} \mathrm{O}_{40}$ and the one with niobium only demonstrated high selectivity for the redox product. The parent catalyst has high activity for redox product which has been shown with its selectivity. But with niobium exchanged catalyst, even though it has high selectivity for redox product, there is a slight increase in the selectivity of the acidic product. The addition of pyridine increases the selectivity for acidic product but is not well reflected with its activity. The catalyst 
exchanged with both niobium and pyridine has high activity for acidic products than redox and the selectivity is also very high for acidic product. 


\section{Chapter 4}

\section{Conclusions}

Microcalorimetry and methanol oxidation studies on polyoxometalate catalysts have been performed. The addition of either niobium or pyridine to the parent $\mathrm{H}_{3} \mathrm{PMo}_{12} \mathrm{O}_{40}$ catalyst results in increased site strength but both have similar heats of adsorption. When both niobium and pyridine are present in the catalyst it does not result in higher ammonia heat of adsorption. However, more strong sites are present when the catalyst is exchanged with both niobium and pyridine.

During methanol oxidation, the parent catalyst $\mathrm{H}_{3} \mathrm{PMo}_{12} \mathrm{O}_{40}$ and the one with niobium only demonstrated high selectivity for the redox product. The parent catalyst has high activity for redox product which has been shown with its selectivity. But with niobium exchanged catalyst, even though it has high selectivity for redox product, there is a slight increase in the selectivity of the acidic product. The addition of pyridine increases the selectivity for acidic product but is not well reflected with its activity. The catalyst exchanged with both niobium and pyridine has high activity for acidic products than redox and the selectivity is also very high for acidic product.

\subsection{Recommendations for Future Works}

This research work focused on determining the acid, base and redox contribution of niobium and pyridine components of heteropolyacid based selective oxidation catalyst. This family of catalysts has been shown to successfully convert butane to maleic acid. While these catalysts can also be used to convert propane to acrylic acid, the presence of 
additional vanadium is important. Previously, in catalyst reactivity studies using propane as a substrate, the presence of vanadium in the niobium and pyridine exchanged catalyst lead to $50 \%$ selectivity of acrylic acid, but without vanadium the selectivity dropped to $6 \%$ for acrylic.

Since vanadium appears essential for high selectivity to acrylic acid, it is clearly providing a separate contribution to the catalyst. It will be interesting to see the effect of the ratio of niobium/pyridine/vanadium in these catalysts, and to know what will be minimum niobium required to stabilize the catalyst. The amount of niobium, pyridine and vanadium can be altered to optimize the catalyst activity. Similar to the studies discussed in this thesis, it is unknown if vanadium contributes to the acid, base or redox component of the catalyst. Thus, performance of ammonia adsorption microcalorimetry and methanol oxidation studies on these catalysts with vanadium could provide evidence for the role of vanadium in the selective oxidation of propane to acrylic acid. 


\section{References}

1. Holles, J.H., et al., A substrate-versatile catalyst for the selective oxidation of light alkanes: I. Reactivity. Journal of Catalysis, 2003. 218(1): p. 42-53.

2. Trifiro, G.C.F.C.F., Selective oxidation by Heterogenous Catalysis. Kluwer Academic/Plenum, New York,2001.

3. Hu, H. and I.E. Wachs, Catalytic Properties of Supported Molybdenum Oxide Catalysts: In Situ Raman and Methanol Oxidation Studies. The Journal of Physical Chemistry, 1995. 99(27): p. 10911-10922.

4. F. Cavani, F.T., Catalysis, 1994: p. 247.

5. G. Centi; V. Iena, F.T.D.G., C.F. Aissi, M. Guelton, J.P.Bonnelle, J. Chem. Soc. Faraday Trans., 1990. (1990): p. 2775.

6. Ai, M., in: 8th International Congress on catalysis, Vol. 5, Dechema, Berlin, 1994: p. 475.

7. Bardin, B.B. and R.J. Davis, Characterization of copper and vanadium containing heteropolyacid catalysts for oxidative dehydrogenation of propane. Applied Catalysis A: General, 1999. 185(2): p. 283-292.

8. Badlani, et al., Methanol : a smart chemical probe molecule. Vol. 75. 2001, Dordrecht, PAYS-BAS: Catalysis Letters Vol. 137-149.

9. Auroux, A. and A. Gervasini, Microcalorimetric study of the acidity and basicity of metal oxide surfaces. The Journal of Physical Chemistry, 1990. 94(16): p. 6371-6379.

10. Bardin, B.B., et al., Acidity of Keggin-Type Heteropolycompounds Evaluated by Catalytic Probe Reactions, Sorption Microcalorimetry, and Density Functional Quantum Chemical Calculations. The Journal of Physical Chemistry B, 1998. 102(52): p. 10817-10825.

11. Jansen, R.J.J.v.V., H. M.; Schwegler, M. A.; van Bekkum,H, Recl. Trav. Chim. Pays-Bas 1994. 113: p. 115.

12. T. Okuhara, N.M., M. Misono, Adv.Catal, 1996. 41: p. 113.

13. Misono, M., Catal. Rev.-Sci. Eng, 1987. 30: p. 269.

14. (ed), C.L.H., Special Thematic Issue on Polyoxometalates. Chem. Rev., 1998. 98(1).

15. Bardin, B.B., R.J. Davis, and M. Neurock, Ammonia Adsorption on Keggin-Type Heteropolyacid Catalysts Explored by Density Functional Quantum Chemistry Calculations. The Journal of Physical Chemistry B, 2000. 104(15): p. 3556-3562.

16. W. Li; W. Ueda; in: R. K . Grasselli; S.T.Oyama, A.M.G.J.E.L.E., 3rd World Congress on oxidation Catalysis. Elsevier, Amsterdam, 1997: p. 433.

17. PC, G., Catal Rev Sci Eng, 1977. 16: p. 37.

18. PY, H., J Catal 1963. 2: p. 211.

19. L, S.F.W., J Catal, 1967. 8: p. 173.

20. PC, G., Adv.Catal, 1972. 22: p. 191.

21. Xie, F., et al., Microcalorimetric study of acid sites on ammonia- and acid-pretreated activated carbon. Carbon, 2000. 38(5): p. 691-700.

22. Vartuli, J.C., et al., Characterization of the Acid Properties of Tungsten/Zirconia Catalysts Using Adsorption Microcalorimetry and n-Pentane Isomerization Activity. Journal of Catalysis, 1999. 187(1): p. 131-138.

23. Farneth, W.E. and R.J. Gorte, Methods for characterizing zeolite acidity. Journal Name: Chemical Reviews; Journal Issue: 3; Other Information: PBD: May 1995, 1995. 95: p. Medium: X; Size: pp. 615-635. 
24. I.V. MISHIN, T.R.B.A.G.I.K., Heats of Adsorption of Ammonia and Correlation of Activity and Acidity in Heterogeneous Catalysis. Springer Science + Business Media, Inc.

Manufactured in The Netherlands., 2005. 11: p. 415- 424.

25. Jovanovic, V.R.V.D.U.M.D., Microcalorimetry in the identification and characterization of the most reactive active sites of heterogeneous catalysts. Topics in Catalysis, 2002. 19(34): p. 241-247.

26. Jozefowicz, L.C., et al., A microcalorimetric investigation of heteropolyacids. Microporous Materials, 1993. 1(5): p. 313-322.

27. Lapkin, A., et al., Microcalorimetric Study of Ammonia Chemisorption on H3PW12O4O Supported onto Mesoporous Synthetic Carbons and SBA-15. Langmuir, 2006. 22(18): p. 7664-7671.

28. Jin, Y.S., et al., Molybdena on Niobium Oxide Catalysts: Preparation and Characterization, in Studies in Surface Science and Catalysis. 1989, Elsevier. p. 525-534.

29. Sun, Q., et al., Dehydration of methanol to dimethyl ether over Nb2O5 and NbOPO4 catalysts: Microcalorimetric and FT-IR studies. Journal of Molecular Catalysis A: Chemical, 2007. 275(1-2): p. 183-193.

30. Petre, A.L., et al., Characterization and reactivity of group III oxides supported on niobium oxide. Catalysis Today, 2003. 78(1-4): p. 377-386.

31. Xue, M., et al., Characterization of acidic and redox properties of Ce-Mo-O catalysts for the selective oxidation of toluene. Thermochimica Acta, 2005. 434(1-2): p. 50-54.

32. W. Ueda, Y.S., Chem.Lett., 1995. 541.

33. Tatibouët, J.M., Methanol oxidation as a catalytic surface probe. Applied Catalysis A: General, 1997. 148(2): p. 213-252.

34. Deo, G. and I.E. Wachs, Reactivity of Supported Vanadium-Oxide Catalysts - The Partial Oxidation of Methanol. Journal of Catalysis, 1994. 146(2): p. 323-334.

35. Machiels, C.J. and A.W. Sleight, Kinetic isotope effect in the selective oxidation of methanol to formaldehyde over some molybdate catalysts. Journal Name: J. Catal.; (United States); Journal Volume: 76:1, 1982: p. Medium: X; Size: Pages: 238-239.

36. Cheng, W.H.C., U.; Ferretti, A.; Firment, L. E.; Groff, R. P.; Machiels, C. J.; McCarron, E. M .; Ohuchi, f.; Staley, R. H.; Sleight,A.W, In heterogenous catalysis Shapiro, B L., Ed,Texas A\&M University Press: College Station, TX, 1984: p. 165.

37. Chowdhry, U.F., A.; Firment, L. E.;Machiels, C. J.; Ohuchi, F.; Sleight, A.W.; Staley, R. H. , Appl. Surf . Sci., 1984. 19: p. 360.

38. Machiels, C.J.C., W. H.; Chowdhry, U.; Farneth, W.E.; Hong, F.; McCarron, E. M.; Sleight, A. W, Appl. Catal, 1986. 25(249).

39. Tatibouët, J.M.G., J. E., J. Catal., 1981. 72: p. 375.

40. Wang, C.-B., G. Deo, and I.E. Wachs, Characterization of Vanadia Sites in V-Silicalite, Vanadia-Silica Cogel, and Silica-Supported Vanadia Catalysts: X-Ray Powder Diffraction, Raman Spectroscopy, Solid-State51V NMR, Temperature-Programmed Reduction, and Methanol Oxidation Studies. Journal of Catalysis, 1998. 178(2): p. 640-648.

41. Barteau, K., et al., UV-visible spectroscopy as a probe of heteropolyacid redox properties: application to liquid phase oxidations. Topics in Catalysis, 2006. 41(1): p. 5562.

42. Lin, M.M., Selective oxidation of propane to acrylic acid with molecular oxygen. Applied Catalysis A: General, 2001. 207(1-2): p. 1-16.

43. T. Okuhara, N.M., M. Misono, Adv.Catal, 2001. 41: p. 443-673. 
44. Davis ME, D.C., Holles JH, Labinger J, A new catalyst for the selective oxidation of butane and propane. Angew Chem Int Ed Engl. , 2002. 41: p. 858-860.

45. Dillon, C.J., et al., A substrate-versatile catalyst for the selective oxidation of light alkanes: Il. Catalyst characterization. Journal of Catalysis, 2003. 218(1): p. 54-66.

46. Holstein, W.L. and C.J. Machiels, Inhibition of Methanol Oxidation by Water Vapor-Effect on Measured Kinetics and Relevance to the Mechanism. Journal of Catalysis, 1996. 162(1): p. 118-124.

47. Wachs, I.E., et al., Redox properties of niobium oxide catalysts. Catalysis Today, 1996. 28(1-2): p. 199-205. 


\title{
Appendix A: Copyright Permission Document
}

This copyright permission is for the use of figure 1-1 in page 3 in this thesis report.

TERMS AND CONDITIONS

\author{
ELSEVIER LICENSE
}

Jun 16, 2010

Rightslink Printable License

This is a License Agreement between Suresh B Bommineni ("You") and Elsevier ("Elsevier") provided by Copyright Clearance Center ("CCC"). The license consists of your order details, the terms and conditions provided by Elsevier, and the payment terms and conditions.

All payments must be made in full to CCC. For payment instructions, please see information listed at the bottom of this form.

\begin{tabular}{|c|c|}
\hline Supplier & $\begin{array}{l}\text { Elsevier Limited } \\
\text { The Boulevard, Langford } \\
\text { Lane } \\
\text { Kidlington, Oxford, OX } 5 \\
\text { 1GB, UK }\end{array}$ \\
\hline Registered Company Number & 1982084 \\
\hline Customer name & Suresh B Bommineni \\
\hline Customer address & $\begin{array}{l}\text { 1801D Woodmar dr } \\
\text { Houghton, MI } 49931\end{array}$ \\
\hline License Number & 2451090231717 \\
\hline License date & Jun 16, 2010 \\
\hline Licensed content publisher & Elsevier \\
\hline Licensed content publication & Journal of Catalysis \\
\hline Licensed content title & $\begin{array}{l}\text { A substrate-versatile } \\
\text { catalyst for the selective } \\
\text { oxidation of light alkanes: I. } \\
\text { Reactivity }\end{array}$ \\
\hline Licensed content author & $\begin{array}{l}\text { Joseph H. Holles, } \\
\text { Christopher J. Dillon, Jay A. } \\
\text { Labinger, Mark E. Davis }\end{array}$ \\
\hline Licensed content date & 15 August 2003 \\
\hline Volume number & 218 \\
\hline Issue number & 1 \\
\hline Pages & 12 \\
\hline Type of Use & Thesis / Dissertation \\
\hline Portion & Figures/tables/illustrations \\
\hline Number of Figures/tables/illustrations & 1 \\
\hline Format & Both print and electronic \\
\hline
\end{tabular}


You are an author of the Elsevier article

Are you translating?

Order Reference Number

Expected publication date

Elsevier VAT number

Permissions price

Value added tax $0.0 \%$

Total

Terms and Conditions
No

No

Dec 2010

GB 494627212

0.00 USD

0.00 USD

0.00 USD

\section{INTRODUCTION}

1.The publisher for this copyrighted material is Elsevier. By clicking "accept" in connection with completing this licensing transaction, you agree that the following terms and conditions apply to this transaction (along with the Billing and Payment terms and conditions established by Copyright Clearance Center, Inc. ("CCC"), at the time that you opened your Rightslink account and that are available at any time at http://myaccount.copyright.com).

\section{GENERAL TERMS}

2. Elsevier hereby grants you permission to reproduce the aforementioned material subject to the terms and conditions indicated.

3. Acknowledgement: If any part of the material to be used (for example, figures) has appeared in our publication with credit or acknowledgement to another source, permission must also be sought from that source. If such permission is not obtained then that material may not be included in your publication/copies. Suitable acknowledgement to the source must be made, either as a footnote or in a reference list at the end of your publication, as follows:

"Reprinted from Publication title, Vol /edition number, Author(s), Title of article / title of chapter, Pages No., Copyright (Year), with permission from Elsevier [OR APPLICABLE SOCIETY COPYRIGHT OWNER]." Also Lancet special credit - "Reprinted from The Lancet, Vol. number, Author(s), Title of article, Pages No., Copyright (Year), with permission from Elsevier."

4. Reproduction of this material is confined to the purpose and/or media for which permission is hereby given.

5. Altering/Modifying Material: Not Permitted. However figures and illustrations may be altered/adapted minimally to serve your work. Any other abbreviations, additions, deletions and/or any other alterations shall be made only with prior written authorization of Elsevier Ltd. (Please contact Elsevier at permissions@elsevier.com) 
6. If the permission fee for the requested use of our material is waived in this instance, please be advised that your future requests for Elsevier materials may attract a fee.

7. Reservation of Rights: Publisher reserves all rights not specifically granted in the combination of (i) the license details provided by you and accepted in the course of this licensing transaction, (ii) these terms and conditions and (iii) CCC's Billing and Payment terms and conditions.

8. License Contingent Upon Payment: While you may exercise the rights licensed immediately upon issuance of the license at the end of the licensing process for the transaction, provided that you have disclosed complete and accurate details of your proposed use, no license is finally effective unless and until full payment is received from you (either by publisher or by CCC) as provided in CCC's Billing and Payment terms and conditions. If full payment is not received on a timely basis, then any license preliminarily granted shall be deemed automatically revoked and shall be void as if never granted. Further, in the event that you breach any of these terms and conditions or any of CCC's Billing and Payment terms and conditions, the license is automatically revoked and shall be void as if never granted. Use of materials as described in a revoked license, as well as any use of the materials beyond the scope of an unrevoked license, may constitute copyright infringement and publisher reserves the right to take any and all action to protect its copyright in the materials.

9. Warranties: Publisher makes no representations or warranties with respect to the licensed material.

10. Indemnity: You hereby indemnify and agree to hold harmless publisher and CCC, and their respective officers, directors, employees and agents, from and against any and all claims arising out of your use of the licensed material other than as specifically authorized pursuant to this license.

11. No Transfer of License: This license is personal to you and may not be sublicensed, assigned, or transferred by you to any other person without publisher's written permission.

12. No Amendment Except in Writing: This license may not be amended except in a writing signed by both parties (or, in the case of publisher, by CCC on publisher's behalf).

13. Objection to Contrary Terms: Publisher hereby objects to any terms contained in any purchase order, acknowledgment, check endorsement or other writing prepared by you, which terms are inconsistent with these terms and conditions or CCC's Billing and Payment terms and conditions. These terms and conditions, together with CCC's Billing and Payment terms and conditions (which are incorporated herein), comprise the entire 
agreement between you and publisher (and CCC) concerning this licensing transaction. In the event of any conflict between your obligations established by these terms and conditions and those established by CCC's Billing and Payment terms and conditions, these terms and conditions shall control.

14. Revocation: Elsevier or Copyright Clearance Center may deny the permissions described in this License at their sole discretion, for any reason or no reason, with a full refund payable to you. Notice of such denial will be made using the contact information provided by you. Failure to receive such notice will not alter or invalidate the denial. In no event will Elsevier or Copyright Clearance Center be responsible or liable for any costs, expenses or damage incurred by you as a result of a denial of your permission request, other than a refund of the amount(s) paid by you to Elsevier and/or Copyright Clearance Center for denied permissions.

\section{LIMITED LICENSE}

The following terms and conditions apply only to specific license types:

15. Translation: This permission is granted for non-exclusive world English rights only unless your license was granted for translation rights. If you licensed translation rights you may only translate this content into the languages you requested. A professional translator must perform all translations and reproduce the content word for word preserving the integrity of the article. If this license is to re-use 1 or 2 figures then permission is granted for non-exclusive world rights in all languages.

16. Website: The following terms and conditions apply to electronic reserve and author websites: Electronic reserve: If licensed material is to be posted to website, the web site is to be password-protected and made available only to bona fide students registered on a relevant course if:

This license was made in connection with a course,

This permission is granted for 1 year only. You may obtain a license for future website posting, All content posted to the web site must maintain the copyright information line on the bottom of each image,

A hyper-text must be included to the Homepage of the journal from which you are licensing at http://www.sciencedirect.com/science/journal/xxxxx or the Elsevier homepage for books at http://www.elsevier.com, and

Central Storage: This license does not include permission for a scanned version of the material to be stored in a central repository such as that provided by Heron/XanEdu.

17. Author website for journals with the following additional clauses:

All content posted to the web site must maintain the copyright information line on the bottom of each image, and he permission granted is limited to the personal version of your paper. You are not allowed to download and post the published electronic version of 
your article (whether PDF or HTML, proof or final version), nor may you scan the Jun printed edition to create an electronic version, A hyper-text must be included to the Homepage of the journal from which you are licensing at http://www.sciencedirect.com/science/journal/xxxxx , As part of our normal production process, you will receive an e-mail notice when your article appears on Elsevier's online service ScienceDirect (www.sciencedirect.com). That e-mail will include the article's Digital Object Identifier (DOI). This number provides the electronic link to the published article and should be included in the posting of your personal version. We ask that you wait until you receive this e-mail and have the DOI to do any posting.

Central Storage: This license does not include permission for a scanned version of the material to be stored in a central repository such as that provided by Heron/XanEdu.

18. Author website for books with the following additional clauses:

Authors are permitted to place a brief summary of their work online only. A hyper-text must be included to the Elsevier homepage at http://www.elsevier.com All content posted to the web site must maintain the copyright information line on the bottom of each image You are not allowed to download and post the published electronic version of your chapter, nor may you scan the printed edition to create an electronic version. Central Storage: This license does not include permission for a scanned version of the material to be stored in a central repository such as that provided by Heron/XanEdu.

19. Website (regular and for author): A hyper-text must be included to the Homepage of the journal from which you are licensing at http://www.sciencedirect.com/science/journal/xxxxx. or for books to the Elsevier homepage at http://www.elsevier.com

20. Thesis/Dissertation: If your license is for use in a thesis/dissertation your thesis may be submitted to your institution in either print or electronic form. Should your thesis be published commercially, please reapply for permission. These requirements include permission for the Library and Archives of Canada to supply single copies, on demand, of the complete thesis and include permission for UMI to supply single copies, on demand, of the complete thesis. Should your thesis be published commercially, please reapply for permission.

\section{Other Conditions: None}

v1.6

Gratis licenses (referencing $\$ 0$ in the Total field) are free. Please retain this printable license for your reference. No payment is required. 
If you would like to pay for this license now, please remit this license along with your payment made payable to "COPYRIGHT CLEARANCE CENTER" otherwise you will be invoiced within 48 hours of the license date. Payment should be in the form of a check or money order referencing your account number and this invoice number RLNK10801059. Once you receive your invoice for this order, you may pay your invoice by credit card.

Please follow instructions provided at that time.

Make Payment To:

Copyright Clearance Center

Dept 001

P.O. Box 843006

Boston, MA 02284-3006

If you find copyrighted material related to this license will not be used and wish to cancel, please contact us referencing this license number 2451090231717 and noting the reason for cancellation.

Questions? customercare@,copyright.com or +1-877-622-5543 (toll free in the US) or $+1-978-646-2777$.

s100.copyright.com/AppDispatchServlet 